\title{
The effect of new oral anticoagulants and tranexamic acid on perioperative blood loss and minor bleeding complications following total hip replacement
}

\author{
Ph.D. Thesis
}

Csaba Gombár M.D.

Supervisor: Krisztián Sisák M.D., Ph.D., habil.

Department of Orthopaedics

Faculty of Medicine, University of Szeged
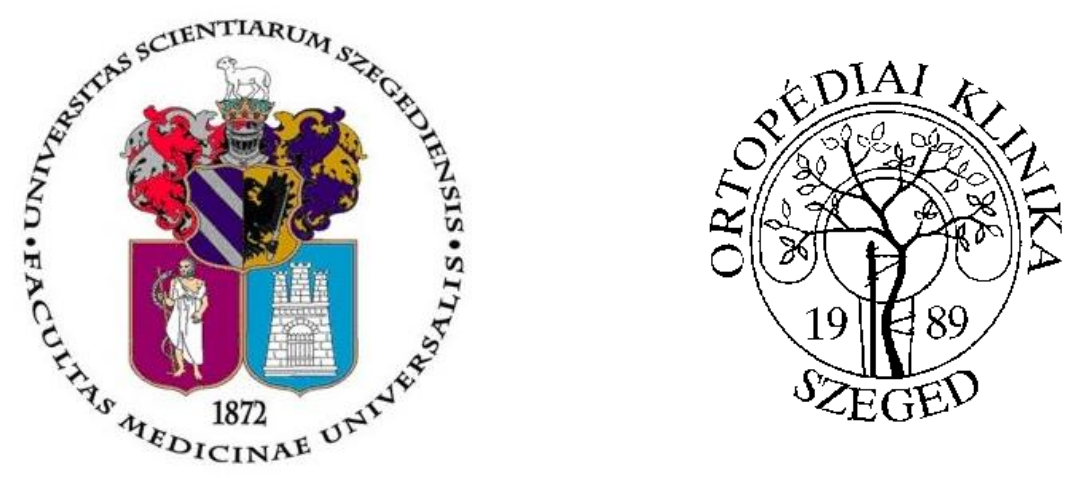

Clinical and Experimental Research for Reconstructive and Organ-Sparing Surgery

Doctoral School of Clinical Medicine

Faculty of Medicine, University of Szeged

Szeged, Hungary 


\section{List of peer-reviewed scientific publications related to the thesis}

I. Gombár C., Horvath G., Gálity H., Sisák K., Tóth K. Comparison of minor bleeding complications using dabigatran or enoxaparin after cemented total hip arthroplasty. Archives of Orthopaedic and Trauma Surgery, 2014;134(4): 449-457.

IF: 1.597

II. Gombár C., Gálity H., Győrfi G., Sohár G., Sisák K., Tóth K. Dabigatran és enoxaparin használata során nyert tapasztalataink csípőprotézis beültetést követően [Our experiences with the use of dabigatran and enoxaparine as thromboprophylactic agents following primary total hip replacement] Magyar Traumatológia, Ortopédia, Kézsebészet, Plasztikai Sebészet 2015;58(1):51-62.

III. Gombár C., Gálity H., Bácsi M., Sisák K. A tranexámsav vérvesztést és kis vérzéses szövődményeket befolyásoló hatása cementes csípő protézis beültetés után [Effect of tranexamic acid on blood loss and soft-tissue swelling following cemented total hip replacement] Orvosi Hetilap 2019;160(12): 456-463.

IF: 0.497

Q3

Total impact factor of original papers related to the thesis: 2.094 


\section{List of scientific publications not related to the subject of the thesis}

I. Gombár C, Tóth K, Kellermann P. Effect of calcaneal-stop procedure on load conditions of pediatric flexible flatfoot Fiziologia-Physiology, Official Journal of the Romanian Society of Physiological Sciences, 2011. supplement, Abstract volume ISSN 1223-2076

II. Sohár G, Gombár C, Gálity H, Tóth K. Veleszületett dongaláb Ponseti szerinti kezelésével elért kezdeti eredményeink [Early results of the Ponseti method for the treatment of congenital clubfoot disease] Magyar Traumatológia, Ortopédia, Kézsebészet, Plasztikai Sebészet 2012;55:(1-2) pp. 67-72.

III. Gombár C, Janositz G, Friebert G, Sisák K. The DePuy Proxima ${ }^{\mathrm{TM}}$ short stem for total hip arthroplasty - Excellent outcome at a minimum of 7 years Journal of Orthopaedic Surgery 2019;27(2):1-6. DOI: 10.1177/2309499019838668

$$
\text { IF: } 1.095 \quad \text { Q2 }
$$

IV. Friebert G, Gombár C, Sisák K. Kiterjedt acetabularis csontdefektusok (Paprosky 3B medence diszkontinuitással) kezelése impaktált csont allograft és ilioischialis cage használatával [Treatment of extensive acetabular bone defects (Paprosky 3B with pelvic discontinuity) with the use of impaction bone grafting and ilioischial cage] Magyar Traumatológia Ortopédia Kézsebészet Plasztikai Sebészet, 2020. 63. évf. 1-2. (accepted, in press)

V. Sisák K, Gombár C, Friebert G, Koós Z. Modern treatment of recurrent patellofemoral instability - combined medial patellofemoral ligament reconstruction and tibial tubercle transfer Acta Chirurgiae Orthopaedicae et Traumatologiae čechoslovaca 2020; 87(6) p. 396 - 403 PMID: 33408004.

$$
\text { IF(2019): } 0.198 \quad \text { Q4 }
$$


VI. Friebert G, Gombár C, Bozó A, Polyák I, Brzózka Á, Sisák K. Differences between proximal bone remodeling in femoral revisions for aseptic loosening and periprosthetic fractures using the Wagner SL stem BMC Musculoskeletal Disorders 2021 Feb 17;22(1):201. doi: 10.1186/s12891-021-04062-6.

IF(2019): $1.879 \quad$ Q2

Cumulative impact factor: 5.266 


\section{$\underline{\text { Summary }}$}

Orthopaedic patients are at the highest risk among all patients for venous thromboembolism (VTE) in terms of perioperative complications. Without any prophylaxis the incidence of deep vein thrombosis ranges from $40 \%$ to $60 \%$ in patients after major orthopaedic surgeries and the incidence of fatal pulmonary embolism is $2 \%$ to $3 \%$ after elective total hip replacement (THR). The ideal method of VTE prophylaxis remains controversial. Recently the new, direct oral anticoagulants (DOACs) for THR have become attractive methods for VTE prevention. Perioperative anticoagulation, although useful for reducing the significant risk of VTE, on the other side of the haemostatic equilibrium, all forms of pharmacological prophylaxis inevitably increase the perioperative bleeding rate. Several studies have proven the blood loss reducing effect of perioperatively administered antifibrinolytic tranexamic acid (TXA), which has become part of perioperative protocols in THR. Development trials with DOACs investigated the major and clinically significant bleeding events as safety endpoints, however, minor bleeding events and wound complications were largely neglected. Most of the studies with TXA describing its blood loss reducing effect used low molecular weight heparins (LMWHs) for VTE prophylaxis. Only very few studies are known to examine TXA's beneficial effect when the new DOACs are used as perioperative anticoagulants. Studies with TXA also neglected to explore its effect on minor bleeding and wound complications.

Our aim was to evaluate the incidence of minor bleeding complications, soft-tissue adverse effects and intraoperative blood loss using DOACs and TXA following cemented THR.

In Study I, consecutive patients were enrolled, who underwent primary cemented THR. Two groups were formed according to the used perioperative anticoagulant. Patients were allocated to enoxaparin (LMWH) group and to dabigatran (DOACs) group. Thigh volume changes, calculated perioperative blood loss, area of haematoma, wound bleeding, duration of wound discharge and intensity of serous wound discharge on the $3^{\text {rd }}$ and $7^{\text {th }}$ postoperative day were examined. We found the same, statistically significant increase in thigh volume in both groups between the initial and $7^{\text {th }}$ postoperative day data, without any difference in thigh volumes with the two different anticoagulants. The calculated perioperative blood loss was the same in both groups. The duration and intensity of serous wound discharge differed significantly between the two groups. Duration of wound discharge after drain removal was 2.2 
$( \pm 2.7)$ days in the dabigatran group and $1.2( \pm 1.9)$ days in the enoxaparin group $(p<0.05)$. Significant increase in serous discharge was found in the dabigatran group $(\mathrm{p}<0.05)$ on the $3^{\text {rd }}$ and $7^{\text {th }}$ postoperative days comparing to the enoxaparin group.

In Study II, we assessed the efficacy of TXA in reducing minor bleeding complications, when rivaroxaban was used for thromboprophylaxis. Consecutive patients undergoing primary cemented THR were studied prospectively. Patients received TXA perioperatively between January 2014 and November 2014 designated as TXA group. We compared this data to a group of patients who underwent the same procedure, between February 2012 and December 2012 (control group), before the introduction of TXA. We investigated the effect of TXA on surgical wound bleeding and wound discharge, area of hematoma on the skin surface, thigh volume changes, calculated perioperative blood loss and transfusion requirement. The extent of postoperative thigh swelling was significantly less in the TXA group $270.3 \mathrm{~mL}$ (129.1-449.0) as compared with the control group $539.8 \mathrm{~mL}(350.0-864.8, \mathrm{p}<0.001)$. TXA significantly reduced wound bleeding during the first 24 hours postoperatively $(\mathrm{p}<0.001)$. The amount of calculated perioperative blood loss was significantly less in the TXA group $(\mathrm{p}<0.001)$. The area of haematoma was significantly smaller in the TXA group $(\mathrm{p}<0.001)$. Transfusion requirement was remarkable lower in the TXA group (15\%, total 26 units vs. 39\%, total 82 units).

Based on our studies we can conclude that dabigatran has the same appropriate antithrombotic effects after THR comparing to enoxaparin. However, the use of dabigatran is associated with an increased incidence of prolonged discharge from the drain site and elevated amount of serous wound discharge. TXA significantly reduces postoperative thigh volume, wound bleeding and area of hematoma on the skin when rivaroxaban is used as the anticoagulant. Further large scale studies could help establish the clinical relevance and longterm outcome of minor bleeding complications. 


\section{$\underline{\text { Table of contents: }}$}

List of peer-reviewed scientific publications related to the thesis 1

List of scientific publications not related to the subject of the thesis ...................................... 2

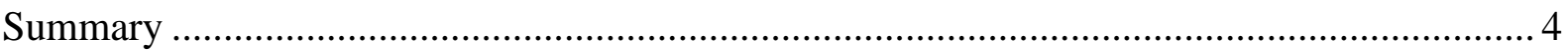

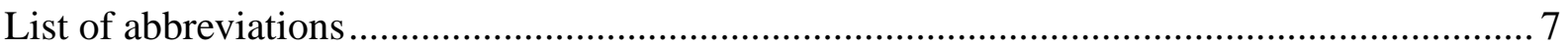

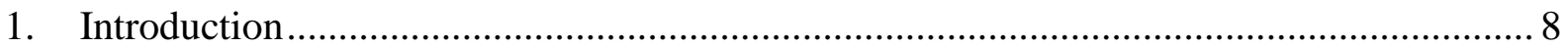

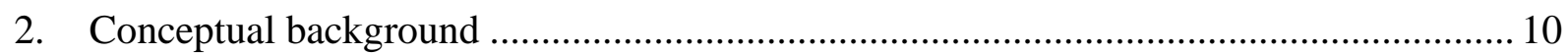

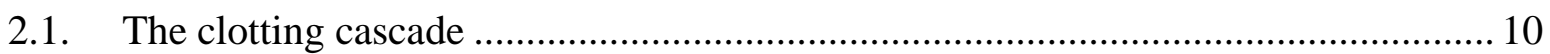

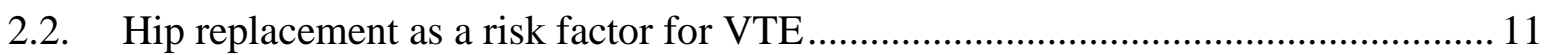

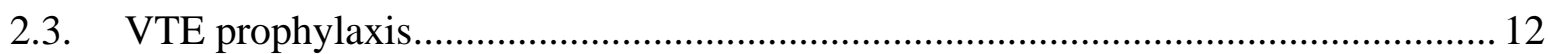

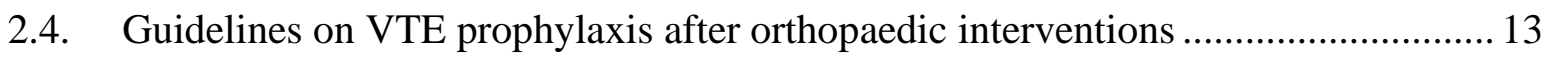

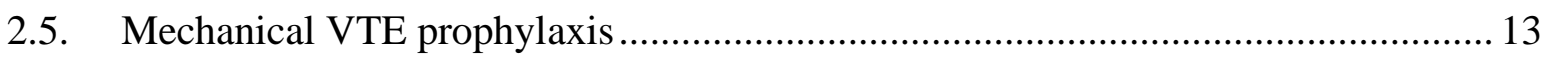

2.6. Pharmacologic VTE prophylaxis for THR according to current guidelines ............. 14

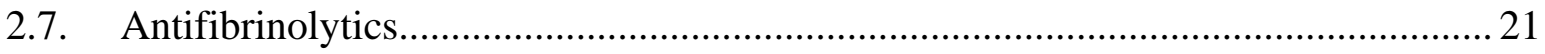

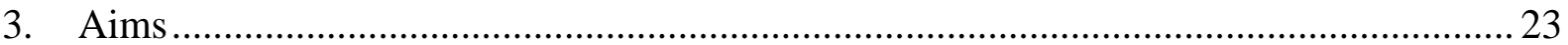

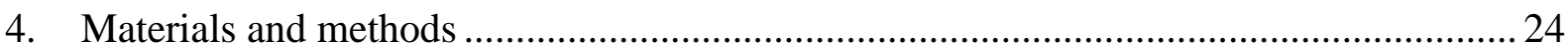

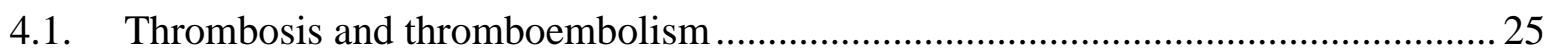

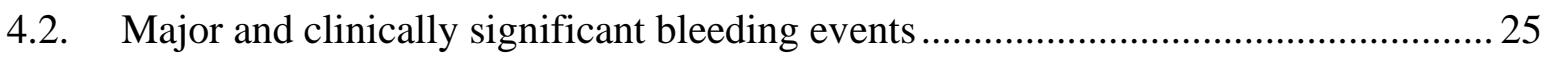

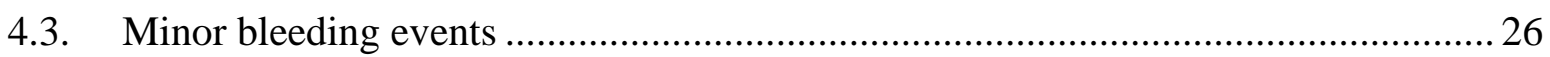

4.4. Bleeding through the surgical incision and serous wound discharge ...................... 26

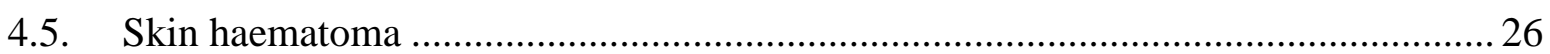

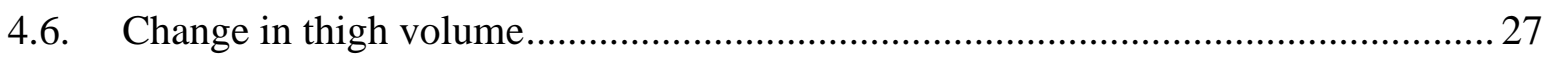

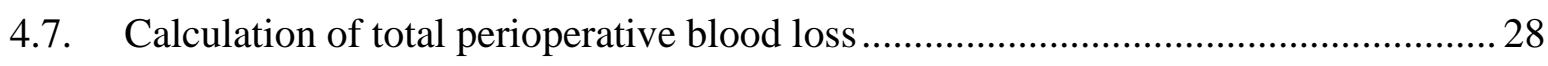

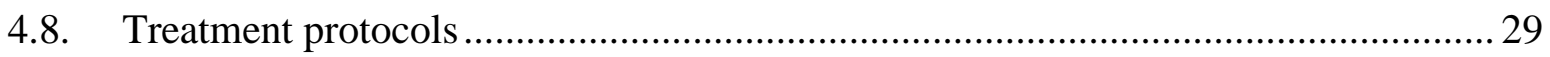

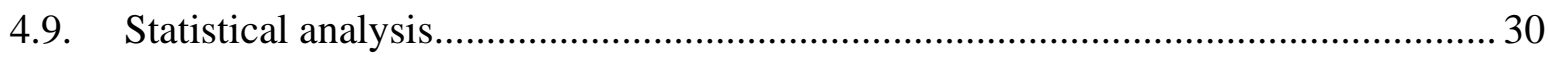

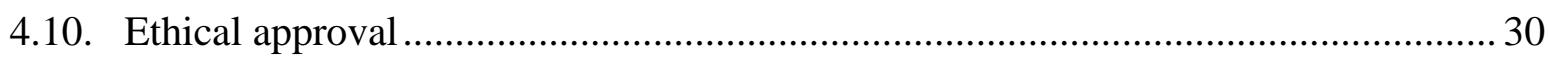

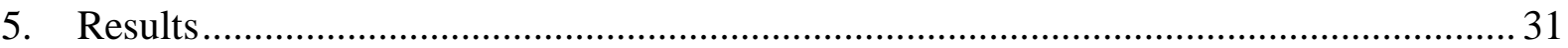

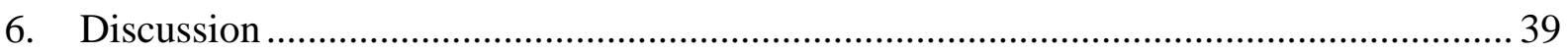

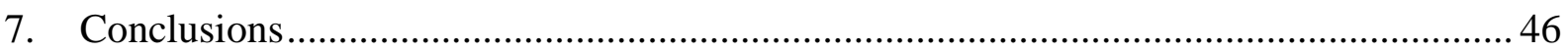

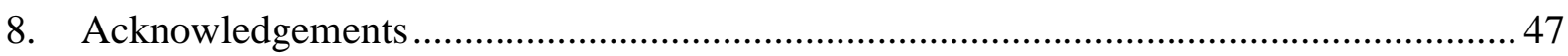

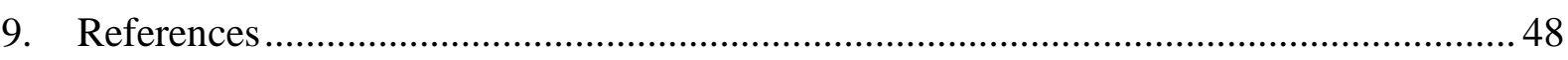

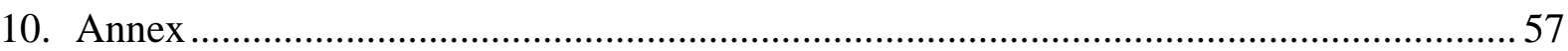




\section{$\underline{\text { List of abbreviations }}$}

AAOS: American Academy of Orthopaedic Surgeons

ACCP: American College of Chest Physicians

aPTT: activated partial thromboplastin time

AT: antithrombin

DOACs: direct oral anticoagulants

DVT: deep vein thrombosis

HIT: heparin induced thrombocytopenia

Hb: haemoglobin

Hct: haematocrit

INR: international normalized ratio

IV: intravenous

LMWHs: low molecular weight heparins

NICE: The National Institute for Health and Care Excellence

NSAIDs: non-steroidal anti-inflammatory drugs

PBV: patient's blood volume

PE: pulmonary embolism

PT: prothrombin time

RBC: red blood cell

SD: standard deviation

SIGN: The Scottish Intercollegiate Guidelines Network

THR: total hip replacement

TXA: tranexamic acid

UFH: Unfractionated heparin

VKA: vitamin $\mathrm{K}$ antagonist

VTE: venous thromboembolism 


\section{Introduction}

In the 1960's, Sir John Charnley developed the basic principles of modern low friction cemented total hip replacement (THR). THR is one of the most commonly performed orthopaedic procedures, with hundreds of thousands of operations performed each year [1]. It can greatly improve the quality of life for patients with end-stage degenerative disease of the hip. The competing risks of thrombotic events and haemorrhagic complications are amongst the major concerns following hip replacement. Perioperative thrombotic complications are a major causes of morbidity and mortality. On the opposite end of the haemostatic equilibrium, perioperative bleeding increases the risk of reoperation, infection, overall length of stay, and hospital costs [2].

Venous thromboembolism (VTE) is a common complication during and after hospitalization for medical, surgical and especially orthopaedic patients. More than half of all hospitalized patients are at risk for VTE. Generally speaking, the surgical patients are at an increased risk compared with medical patients and orthopaedic patients are at an even higher risk of postoperative thrombotic complications [3]. Without any prophylaxis the incidence of deep vein thrombosis (DVT) in medical and general surgical patients is in the range of $10 \%$ to $40 \%$; in comparison, the incidence of DVT ranges from $40 \%$ to $60 \%$ in patients after major orthopaedic surgeries $[4,5]$. Similarly, the incidence of fatal pulmonary embolism (PE) in hospitalized patients is $0.1 \%$ to $0.8 \%$ after elective general surgery, whilst it is $2 \%$ to $3 \%$ after elective hip replacement. Death within one month of diagnosis occurs in approximately $6 \%$ of DVT patients and approximately $12 \%$ of PE patients $[6,7]$.

Orthopaedic patients are at the highest risk among all patients for VTE in terms of perioperative complications. In the 19th century Virchow described the three factors that affect coagulation within a blood vessel. The factors included in Virchow's triad are the stasis or stoppage of blood flow, vascular endothelial damage and hypercoagulability of blood. Risk factors, which relate to these factors, can predict which patients will be most likely to develop VTE complications. In an orthopaedic patient during the perioperative period, all of the above mentioned pathophysiologic processes are frequently present: 1) use of tourniquet, immobilization and bed rest cause venous blood stasis; 2) surgical manipulation of the limb cause endothelial vascular injuries; 3) trauma increases the number of thromboplastin agents; 
and 4) use of polymethylmethacrylate bone cement increase hypercoagulability [8]. Therefore, in patients undergoing orthopaedic surgery VTE prophylaxis and adherence to the respective guidelines are of paramount importance [9]. Although there are many national and international thromboprophylaxis guidelines, which have recommended thromboprophylaxis for patients admitted to the hospital, only $60 \%$ to $75 \%$ of surgical patients actually receive adequate thromboprophylaxis [8-12].

Perioperative anticoagulation, although useful for reducing and preventing the significant risk of VTE after orthopaedic surgery, on the other side of the haemostatic equilibrium, all forms of pharmacological prophylaxis increase the risk of perioperative bleeding complications [13]. Major perioperative bleeding increases the risk of reoperation, length of stay, and hospital costs. Severe anaemia (haemoglobin $<8 \mathrm{mg} / \mathrm{dL}$ ) is associated with increased postoperative mortality and poor functional recovery. Allogeneic blood transfusion is a traditional and frequently used method to treat a patient's low and symptomatic postoperative haemoglobin (Hb) level, however it is well known, that it can potentially extend the rehabilitation time and the length of hospital stay and has a number of potential adverse effects [14]. In addition to this, transfusion inhibits the immune system and increases the chance of infection. Various methods are available for both orthopaedic surgeons and anaesthesiologists to reduce perioperative blood loss and prevent the need for allogeneic blood transfusion, including meticulous surgical technique, controlled hypotension, regional anaesthesia, autologous blood transfusion, intraoperative blood salvage, and the use of erythropoietin and antifibrinolytic agents [14]. During the previous decade several studies have proven the beneficial, blood loss reducing effect of perioperatively administered antifibrinolytic drugs in orthopaedic patients [15]. Amongst them, tranexamic acid has become a regular part of perioperative protocols in lower limb arthroplasty [16].

Minor bleeding complications related to the surgical wound and to the soft-tissue envelope around the surgical site and their effects on functional outcomes are as significant concerns for orthopaedic surgeons as major bleeding complications are. The wound haematoma following a joint replacement can potentially lead to a periprosthetic joint infection or to joint stiffness and a compromised functional outcome. These type of complications were neglected previously, however during the last few years they have received increased attention as potentially preventable complications. 
Bleeding risk and possible contraindication to antithrombotic agents must be assessed before initiating thromboprophylaxis. Although potential risk of bleeding complications has not been traditionally addressed as a part of other guidelines, in 2011 the American Academy of Orthopaedic Surgeons' (AAOS) work group stated the seriousness of these concerns during preparing the update for American College of Chest Physicians' (ACCP) guidelines on VTE prophylaxis [17]. Bleeding complications and their consequences are a major concern for surgeons during chemoprophylaxis, and should be considered when deciding on the type and time of initiation of the therapy. Personalized risk stratification has become an important part of the new era of VTE prophylaxis to reduce all types of perioperative bleeding risks to the lowest possible level.

\section{Conceptual background}

\subsection{The clotting cascade}

'The clotting mechanism consists of self-regulating processes that result in the production of a fibrin thrombus. These processes are controlled by inactive cofactors that, when activated, promote or accelerate clotting (Figure 1). These processes usually occur on the surfaces of the platelets or macrophages, or in the endothelial cells, and are initiated by two specific pathways: extrinsic and intrinsic. The extrinsic pathway is initiated as a result of activation of tissue lipoproteins resulting from mechanical injuries such as trauma and/or surgery. The intrinsic pathway involves circulating plasma factors. Both pathways are found at the level of factor X, transformed into factor $\mathrm{Xa}$. This factor promotes the conversion of prothrombin into thrombin (factor II), which in turn, transforms the fibrinogen into fibrin, this being the key step for the formation of the thrombus. The plasmin digests the fibrin, as well as inactivating the V and VIII factors and fibrinogen, restoring normal blood flow. There are three anticlotting mechanisms that prevent the formation of thrombi: antithrombin (AT), C and S proteins, and the extrinsic pathway inhibition (tissue factor). In case of surgery or trauma, there is a decrease in circulating AT level, which stimulates the clotting process. Studies have shown that this decrease in AT is greater, and remains for longer in THR than in cases of general surgery. In a previous study low AT levels were found in patients diagnosed with DVT after surgery [18]'. 
Figure 1 The haemostatic equilibrium: fine balance between coagulation and fibrinolysis. In Hungary currently available anticoagulants and antifibrinolytics for patients undergoing THR also can be seen with their action of mechanism. More information in the text below.

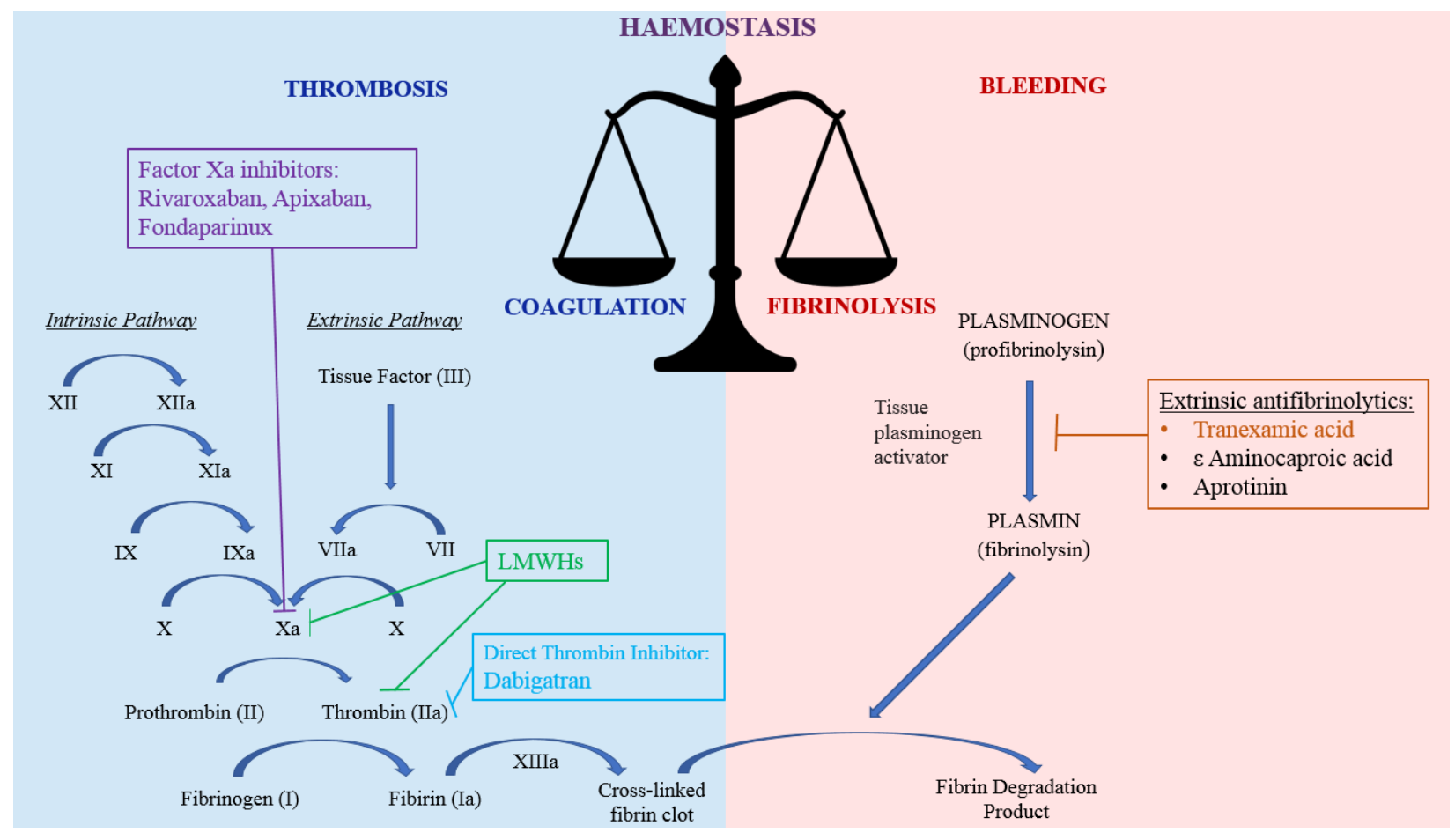

\subsection{Hip replacement as a risk factor for VTE}

There have been many reported risk factors for VTE, these include age, obesity, varicose veins, family history of VTE, thrombophilias, combined oral contraceptives, hormone replacement therapy, anti-oestrogens, pregnancy, puerperium, immobilization, long-haul travel, hospitalization, anaesthesia and central venous catheters [19]. Practically every patient admitted to a hospital has at least one of the above mentioned risk factors. Hip replacement is a major orthopaedic intervention, meaning it is a strong risk factor for VTE. Because the risk factors are cumulative, any other associated condition belonging to the moderate or weak risk factors may increase the chance for VTE (Table 1) [12]. 
Table 1 Severity of risk factors for VTE

\begin{tabular}{|l|l|l|}
\hline \multicolumn{2}{|l|}{ Risk factors for VTE: } \\
\hline Strong & Moderate & Weak \\
$\bullet$ fracture of the hip or leg & $\bullet$ arthroscopic knee surgery & $\bullet$ bed rest $>$ 3 days \\
$\bullet$ hip or knee replacement & $\bullet$ central venous catheters & $\bullet$ immobilization or bedridden \\
$\bullet$ major general surgery & $\bullet$ chemotherapy & $\bullet$ advanced age \\
$\bullet$ major trauma & $\bullet$ congestive heart or respiratory failure & $\bullet$ laparoscopic surgery \\
$\bullet$ spinal cord injury (SCI) & $\bullet$ hormone replacement therapy & $\bullet$ obesity \\
& $\bullet$ malignancy & $\bullet$ pregnancy/antepartum \\
& $\bullet$ oral contraceptive therapy & \\
& $\bullet$ paralytic stroke & \\
& $\bullet$ pregnancy/postpartum \\
& $\bullet$ previous VTE & \\
& $\bullet$ thrombophilia & \\
\hline
\end{tabular}

A risk stratification of the risk for VTE classifies orthopaedic patients who have undergone hip or knee arthroplasty in the highest risk category [8]. Randomized clinical trials have concluded that the rates of venographically documented DVT and proximal DVT seven to fourteen days after major orthopaedic surgery in patients who did not receive any VTE prophylaxis are approximately $40 \%$ to $60 \%$ and $10 \%$ to $30 \%$, respectively [19]. After discharge from hospital, these orthopaedic patients are still at risk for VTE. Hypercoagulability can persist, therefore VTE can occur up to three months [20] postoperatively and is the most common cause for readmission after THR [19]. 20\% of THR patients with negative venogram at discharge and no VTE prophylaxis had a new DVT that developed over the subsequent three weeks based on repeated venogram [21]. With routine VTE prophylaxis in orthopaedic patients, fatal PE is uncommon, and the rates of symptomatic VTE within three months have been reduced to $1.3 \%$ to $10 \%[8,19]$.

\subsection{VTE prophylaxis}

DVT of the limbs is the development of a blood clot in one of the major deep veins in the extremities, which leads to impaired venous blood flow. It most frequently occurs in the lower limbs, causing leg swelling and pain. PE is a consequence of thrombus formation in the deep venous system of the lower extremities. The deep venous thrombi might embolize to the 
pulmonary vasculature, resulting in a PE. VTE prophylaxis consists of mechanical and pharmacologic measures to reduce the risk of deep vein thrombosis and pulmonary embolism.

\subsection{Guidelines on VTE prophylaxis after orthopaedic interventions}

The most frequently cited international guidelines recommending anticoagulation for patient undergoing hip arthroplasty are:

1) American College of Chest Physicians (ACCP): "Prevention of Venous Thromboembolism in Orthopaedic Surgery Patients: Antithrombotic Therapy and Prevention of Thrombosis" (9th edition, published in 2012) [7]. In 2016, the ACCP updated recommendations on 12 topics that were in the 9th edition of their guidelines, and addressed three new topics. However these did not change the recommendations regarding orthopaedic patients [22].

2) American Academy of Orthopaedic Surgeons (AAOS): “Clinical Practice Guideline on Preventing Venous Thromboembolic Disease in Patients Undergoing Elective Hip and Knee Arthroplasty" (published in 2012) [23].

3) Scottish Intercollegiate Guidelines Network (SIGN): "Prevention and management of venous thromboembolism" (published in 2010, updated in 2015) [11].

4) British National Institute for Health and Care Excellence (NICE): "Venous thromboembolism in over 16s: reducing the risk of hospital-acquired deep vein thrombosis or pulmonary embolism" (published in 2018, updated in 2019) [24].

5) The last available Hungarian guideline on VTE prophylaxis is 'Reduction and treatment of thromboembolism' (published in February 2010, and was valid until $31^{\text {st }}$ December 2013, has not been updated). It contains the recommendation on thromboprophylaxis for patients after THR [25].

\subsection{Mechanical VTE prophylaxis}

The mechanical methods for VTE prophylaxis include early mobilization, graduated compression stockings, intermittent pneumatic compression device and venous foot pumps 
[24]. Advantages of mechanical VTE prophylaxis include the lack of bleeding potential, no need for laboratory monitoring and no clinically important side effects [19, 24]. Furthermore, the effectiveness of anticoagulants may be enhanced by some mechanical methods. Disadvantages of mechanical VTE prophylaxis methods include the difficulty of implementation and compliance issues due to the limited movement of the patient and the discomfort they may bring [18], needing to be worn continuously pre-, intra- and postoperatively for 72 hours. There is also a lack of strong evidence that any of the mechanical VTE prophylaxis methods can reduce the risk of death or PE. There are also frequent contraindications to their use (fragile 'tissue paper' skin, venous leg ulcers, suspected or proven peripheral arterial disease, etc.) [24].

Early mobilization is probably the most simple and easily applicable method of VTE prophylaxis [18]. Early walking has been associated with a lower incidence of post-THR symptomatic VTE. It must be noted that although the early and frequent ambulation of hospitalized patients at risk for VTE is an important principle of patient care, the majority of hospital-associated, symptomatic VTE events occur after the patients have started to ambulate [26]. Therefore, mobilization alone does not provide adequate VTE prophylaxis for hospitalized patients and should be regarded with caution [19].

The latest available guidelines from the ACCP (2012) suggest the use of mechanical methods in addition to pharmacological prophylaxis during hospitalization in patients with high risk for VTE after major orthopaedic surgery. In particular, the use of ICPDs with portable batteries is recommended in order to achieve maximum compliance [7]. SIGN (2010) and Hungarian (2010) guidelines both mention mechanical methods as an additional way to complement pharmacological prophylaxis for VTE prevention $[11,25]$.

\subsection{Pharmacologic VTE prophylaxis for THR according to current guidelines}

The current guidelines recommend the use of pharmacologic VTE prophylaxis for 28-35 days and suggest the use of additional mechanical VTE prophylaxis after THR [7, 11, 24, 25, 27]. 


\subsubsection{Acetylsalicylic acid}

Acetylsalicylic acid is a widely used, inexpensive, orally administered medication which is controversial as a solo thromboprophylactic agent. It irreversibly inhibits the COX-1 enzyme, preventing the formation of thromboxane A2, which is an important cofactor for thrombocyte activation and aggregation. Acetylsalicylic acid is suspected to downregulate tissue factor expression, thrombin formation, and reduce thrombin-mediated coagulant reactions [8].

The 8th ACCP guidelines in 2008 clearly recommended against the use of aspirin alone as VTE prophylaxis for any patient group including orthopaedic patients [19]. In contrast to this, the 9th ACCP guidelines in 2012, after accepting the suggestions of the AAOS, do recommend the use of acetylsalicylic acid as VTE prophylaxis for patients undergoing THR, however the same guideline recommends the use of LMWH in preference to other agents including acetylsalicylic acid [7].

The SIGN guidelines in 2010 gave straightforward advice for physicians about the use of acetylsalicylic acid. It is not recommended as the sole pharmacological agent for VTE prophylaxis in orthopaedic patients, because other agents are more effective for prevention of VTE [11].

In Hungary, the last available guideline gave clear recommendation against the use of acetylsalicylic acid as VTE prophylaxis in patient after THR [25].

Generally, the use of aspirin as a VTE prophylactic agent in orthopaedic patients remains controversial, because of the limited quality of the available evidence. According to recently published meta-analyses and review papers, aspirin seems to be a suitable drug for prevention of VTE after THR in low risk patients, however further well-designed randomised controlled trials are needed for the correct dosage and duration of administration of aspirin [28, 29].

\subsubsection{Vitamin $K$ antagonists}

Vitamin K antagonists (VKAs) were the first classic oral anticoagulants. VKAs impair the biosynthesis of functional vitamin $\mathrm{K}$-dependent proteins by the competitive inhibition of vitamin $\mathrm{K}$ epoxide reductase. This action limits the production of carboxylated vitamin $\mathrm{K}-$ dependent coagulation factors II, VII, IX, and X, as well as coagulation regulatory factors protein $\mathrm{C}$ and protein $\mathrm{S}$. VKAs have a narrow therapeutic window, and determination of their 
therapeutic dose in clinical practice is challenging. Adverse events, such as bleeding, frequently occurred among individuals initiating therapy [30]. A therapeutic INR (international normalized ratio) range of 2.0 to 3.0 with a target INR of 2.5 is recommended rather than a lower or higher range, therefore monitoring of the INR and dosage adjustment are always required. When warfarin is administered, an initial effect on INR usually occurs within the first two to three days. Consequently, when a rapid anticoagulant effect is required, heparin or LMWH should be administered concurrently. This administration should be overlapped for at least two days with warfarin until INR reaches the therapeutic range to allow for further reduction of factors $\mathrm{X}$ and II $[8,31]$.

VKAs are recommended by the latest ACCP guidelines for VTE prophylaxis in patients undergoing THR [7]. VKAs are not mentioned in the NICE and SIGN guidelines as an optional thromboprophylactic method for elective THR $[11,24]$. The last available Hungarian guideline in 2010 gave clear recommendation against the use of VKAs as VTE prophylaxis in patient after THR [25].

\subsubsection{Unfractionated heparin}

Unfractionated heparin (UFH) is a heterogeneous mixture of glycosaminoglycans that binds to AT via a unique pentasaccharide sequence and catalyses the inactivation of thrombin, factor $\mathrm{Xa}$ and other clotting enzymes [32]. The heparin-AT complex inactivates thrombin (factor IIa) and factors Xa, IXa, XIa and XIIa. Heparin must be administrated parenterally. The two preferred administration routes are continuous intravenous (IV) infusion and subcutaneous [8]. The use of UFH may lead to haemorrhagic complications. Because anticoagulant response varies among patients, monitoring UFH with tests and adjusting the dose is standard practice. The anticoagulant effect of UFH is usually monitored using the activated partial thromboplastin time (aPTT). The anticoagulant effects of the UFH can rapidly be reversed with the use of IV protamine sulphate [32]. UFH may also lead to non-haemorrhagic side effects, such as heparininduced thrombocytopenia (HIT) and osteoporosis, because it also inhibits osteoblast formation and activates osteoclasts promoting bone loss [8, 33]. HIT is an immune mediated adverse drug reaction caused by the emergence of antibodies that activate platelets in the presence of heparin. Despite thrombocytopenia, the bleeding complications are rare. HIT tends to cause 
hypercoagulable condition associated with thromboembolic complications involving both the arterial and venous systems [34].

UFH is recommended by the latest ACCP guidelines for VTE prophylaxis in patients undergoing THR [7]. UFH is not mentioned in the NICE and SIGN guidelines as an optional thromboprophylactic method for elective THR $[11,24]$. The last available Hungarian guideline in 2010 gave clear recommendation against the use of UFH as VTE prophylaxis in patient after THR [25].

\subsubsection{Low molecular weight heparins}

Low molecular weight heparins (LMWHs) are derived from UFH by chemical or enzymatic depolymerization. Their molecular weight is approximately one-third that of UFH. LMWHs have a more favourable benefit-to-risk ratio with superior pharmacokinetic properties compared with UFH. The inhibitory activity of LMWHs against factor Xa is greater than thrombin and exhibits less binding to cells and proteins (Figure 1), consequently, LMWH preparations have more predictable pharmacokinetic and pharmacodynamic properties, a longer half-life and a lower risk of non-haemorrhagic side effects than UFH. They are administered daily in one or two doses depending on the required dose and current guidelines. LMWHs are subcutaneous injections without the need of monitoring. An uncommon but potentially devastating complication of LMWHs is HIT syndrome. The risk for HIT is much less than what has been reported with UFH (0.2\% vs. $2.6 \%)$ [35]. In summary, the use of LMWHs are more convenient than UFH, therefore they have replaced UFH for almost all clinical indications [8, 32].

Over the last 20 years, many studies reported the superiority of LMWH over the previously mentioned anticoagulants [19, 27, 36-38]. In patients undergoing orthopaedic interventions LMWHs are more efficacious than aspirin or either adjusted-dose UFH or warfarin, when used for the prevention of DVT and their administration also results in significantly less minor bleeding complications when compared with UFH, but significantly more minor bleeding when compared to warfarin and aspirin [19, 27, 37]. LMWHs have become standard thromboprophylactic drugs amongst orthopaedic patients [36]. Enoxaparin, is 
one of the most favoured subcutaneously administered antithrombotic agent in Europe, and was used as the comparator during clinical trials with the direct oral anticoagulants (DOACs).

The latest ACCP guidelines recommended LMWH as the optimal method for VTE prophylaxis in patients undergoing THR [7]. The NICE and SIGN guidelines and also the last available Hungarian guidelines on VTE prophylaxis gave recommendation for the use of LMWH in preference to other agents as alternatives for VTE prophylaxis in patient after THR [7, 11, 25]. Recent NICE guidelines suggest LMWH for 10 days and then aspirin for another 28 days or LMWH for 28 days in combination with anti-embolism stockings until discharge for patients undergoing elective THR [24]. LMWH should be considered the gold standard for VTE prophylaxis in orthopaedic patients.

\subsubsection{Fondaparinux}

Fondaparinux is a synthetic pentasaccharide with specific anti-Xa activity. Pharmacologically, fondaparinux binds to AT and produces a conformational change at the reactive site of AT that enhances its reactivity with factor Xa (Figure 1). The daily dose of fondaparinux is $2.5 \mathrm{mg}$ subcutaneously for VTE prophylaxis [32]. A benefit of fondaparinux over other injectable agents such as UFH and LMWH is that it does not inactivate thrombin, has no effect on platelets and does not cause HIT [8, 18].

The latest ACCP guidelines recommend fondaparinux as a method of VTE prophylaxis for patients undergoing THR [7]. However, the same guidelines report that the close balance between advantages and disadvantages of fondaparinux makes its use less appealing than LMWH for extended VTE prophylaxis [7]. SIGN and Hungarian guidelines mention fondaparinux as an alternative method for VTE prophylaxis [11, 25]. The recent NICE guidelines do not mention fondaparinux for patient undergoing elective THR, however in case of hip fractures it is still a recommended method [24]. In Hungary fondaparinux is still available, however the national health insurance does not support its prescription for orthopaedic patients undergoing any elective arthroplasty. 


\subsubsection{Direct oral anticoagulants}

Compared with VKAs, the new direct oral anticoagulants (DOACs) [39] have the advantage of administering them at fixed doses without the need of laboratory monitoring. Subsequently, they have the potential to overcome several drawbacks of VKAs [7,8]. There are several commercially available DOACs that are licensed for thromboprophylaxis.

\subsubsection{Apixaban}

Apixaban is an oral direct inhibitor of factor $\mathrm{Xa}$ that has been approved for VTE prophylaxis following THR (Figure 1). There are studies that compared the efficacy of apixaban versus enoxaparin that led to the approval of apixaban for VTE prophylaxis after major orthopaedic interventions [40, 41] The current recommended dosage for VTE prophylaxis after THR is $2.5 \mathrm{mg}$ twice daily starting 12 to 24 hours after surgery and continuing for 35 days for THR $[8,42]$. Apixaban is also recommended by the latest NICE and ACCP guidelines as options for the prevention of venous thromboembolism in adults undergoing elective THR [7, 24]. The latest SIGN and Hungarian guidelines on thromboprophylaxis were released in 2010. Apixaban, a year later received its European marketing authorization for VTE prophylaxis in patients undergoing elective THR, therefore apixaban was not even mentioned in these guidelines $[11,25]$. Despite this, apixaban is available in Hungary and national health insurance recommends its prescription and its use for patients undergoing elective arthroplasty [43].

\subsubsection{Edoxaban}

Edoxaban is a novel, orally administered direct inhibitor of factor Xa. Edoxaban $15 \mathrm{mg}$ and $30 \mathrm{mg}$ tablets were approved for prevention of deep vein thrombosis in patients undergoing elective arthroplasty in 2011 in Japan. The use of edoxaban is authorized in Europe to treat and prevent DVT and PE from re-occurring, to prevent stroke and systemic embolism in patients with non-valvular atrial fibrillation. It also should be noted that edoxaban is only approved for VTE prophylaxis in Japan. It has not yet approved for this indication in Europe and the United States because its suspected elevated bleeding risk in special subgroups [44, 45]. 


\subsubsection{Rivaroxaban}

Rivaroxaban is also an orally administered direct factor Xa inhibitor (Figure 1). In 2008, rivaroxaban received marketing authorization for VTE prophylaxis in adult patients undergoing elective THR [46]. It was found to be more effective than enoxaparin in preventing VTE after THR [47, 48]. Rivaroxaban is administered for VTE prophylaxis after elective THR and TKR in a fixed daily oral dose of $10 \mathrm{mg}$ started 6-10 hours after surgery once haemostasis has been established $[8,46]$. The latest ACCP guidelines recommend rivaroxaban as a method of VTE prophylaxis in patients undergoing THR [7]. Rivaroxaban is also recommended by the latest NICE, SIGN and Hungarian guidelines as an option for the prevention of VTE in adults undergoing elective THR [11, 24, 25].

\subsubsection{Dabigatran etexilate}

Dabigatran is a selective, reversible, direct thrombin (factor II) inhibitor (Figure 1). It is administered as dabigatran etexilate, which is an orally absorbable prodrug, since dabigatran itself is a strongly polar molecule that is not absorbed from the gut. Phase III clinical studies evaluated the use of dabigatran etexilate for VTE prophylaxis after elective THR and it has been approved in many countries. Its efficacy was analysed in studies that compared dabigatran etexilate (220 or $150 \mathrm{mg}$ per day) with enoxaparin in patients undergoing THR [49-52]. Studies reported that dabigatran etexilate was as effective as enoxaparin for VTE prophylaxis. For VTE prophylaxis, the dosing regimen of dabigatran is $150 \mathrm{mg}$ or $220 \mathrm{mg}$ daily, starting with a half dose 1-4 hours after surgery [24, 25]. In 2012, Uchino et al [53] reported that there is an association between dabigatran and an increased risk of myocardial infarction or acute coronary syndrome in a number of patients when tested against different controls [8]. Despite these findings, the latest ACCP, SIGN and Hungarian guidelines recommend dabigatran as a method of VTE prophylaxis in patients undergoing THR [7, 11, 25]. The latest NICE guideline is more conservative, because it suggests that dabigatran should only be used as a second line drug for VTE prophylaxis after THR if rivaroxaban or LMWHs are not available [24]. 


\subsection{Antifibrinolytics}

Antifibrinolytics are tranexamic acid (TXA), aprotinin and $\varepsilon$-aminocaproic acid. They utilize different mechanisms to inhibit the dissolution of blood clots. A number of studies have investigated their efficacy during perioperative period in THR [54, 55]. TXA is cheaper and safer than aprotinin and approximately ten times more potent and less toxic than $\varepsilon$-aminocaproic acid with overall good penetration into joints $[56,57]$. The use of TXA has gained significant popularity during major orthopaedic interventions [54].

\subsubsection{Tranexamic acid}

TXA is a synthetic antifibrinolytic agent, which competitively inhibits the conversion of plasminogen to plasmin, preventing fibrin degradation and preserving the stable framework of fibrin's matrix structure. During the last decade TXA has become a regular part of perioperative protocols in lower limb arthroplasty by the virtue of reducing perioperative blood loss and lowering transfusion rates. In the United Kingdom, TXA is recommended for all surgery where blood loss is expected to be greater than $500 \mathrm{ml}$ [58]. TXA is not approved by the Food and Drug Administration for this purpose in the United States. In Hungary, slow intravenous administration of daily 500-1000 mg TXA (divided into two or three doses) was authorized for prophylaxis of local fibrinolysis $[59,60]$.

Most of the studies have been carried out in orthopaedic surgery, where tranexamic acid has been shown to reduce the rate of allogeneic blood transfusion by up to 69\% [15] after hip and knee surgery, without the increased risk of complications, including thromboembolic events $[55,61]$. Whilst its effectiveness and safety have been examined by several studies [54, 62], the route, timing and dosage of TXA using in THR is still controversial [63]. It can be applied orally, directly to the surgical site or through intravenous administration starting pre-, intra- or postoperatively [16, 64-67].

Absolute contraindications to the administration of TXA include known allergy to TXA, known defective colour vision, greater than 3 hours after traumatic injury, pre-existing active thromboembolic disorder, disseminated intravascular coagulation or fibrinolytic conditions following consumptive coagulopathy, acute renal failure, coronary or vascular stents placed within the last twelve months and acute subarachnoid haemorrhage. Relative contraindications 
might include known epilepsy, renal dysfunction, high risk of venous or arterial thrombosis, or pre-existing coagulopathy or oral anticoagulant treatment $[68,69]$. 


\section{3. $\underline{\text { Aims }}$}

The data from development trials suggests that the thromboprophylactic efficacies of the new DOACs are at least equivalent or potentially superior to the clinical trial comparator LMWH, enoxaparin. However, these new agents might be associated with a potentially higher bleeding tendency $[36,47,49-51,70,71]$. Several reviews and trials warned of a potentially higher postoperative bleeding and wound infection rate of DOACs [72, 73]. Our clinical experiences with elevated serous wound discharge enticed us to design a prospective study based on our everyday experience and explore the bleeding profile of DOACs focusing on minor bleeding. The number and severity of minor bleeding and wound complications were neglected during the dose-finding and dose-ranging clinical trials. Orthopaedic surgeons encounter these problems frequently, and indirectly the number of these complications determine the adherence to international and national VTE prophylaxis guidelines. Clinical trials with dabigatran etexilate for THR focused on major and clinically significant bleeding complications, as safety endpoints, with little attention paid to surgically relevant outcomes, such as wound healing, drainage, and surgical site infection [49-51].

1. In Study I our aim was to compare the safety profile of enoxaparin and dabigatran etexilate in the use of primary THR, with particular attention to minor haemorrhagic and soft tissue adverse effects during the early postoperative period.

Most of the studies describing the perioperative major bleeding complication and blood loss reduction effect of TXA, used LMWHs for VTE prophylaxis. Only a very few studies are known to examine TXA's beneficial effect when the new DOACs are used as perioperative anticoagulants in patients undergoing cemented THR [74, 75]. Studies with TXA also neglected to explore its effect on minor bleeding and wound complications.

2. In Study II our aim was to prospectively assess the efficacy of tranexamic acid on postoperative blood loss when rivaroxaban is used as thromboprophylaxis after cemented THR. In addition, we examined whether TXA has any effect on minor bleeding complication. 


\section{Materials and methods}

Routine preoperative assessment included laboratory tests, such as renal and liver function tests, aPTT, prothrombin time (PT) and INR. Patients were excluded if they had had renal and/or hepatic dysfunction, a history of coagulopathy, previous thromboembolic event, previous cardiovascular implants or bypass surgery, prolonged anticoagulant therapy or extended antiplatelet drug intake (acenocoumarol, warfarin, clopidogrel, acetylsalicylic acid more than 100 milligrams), known epilepsy or allergy to tranexamic acid or to the administered anticoagulant. If patients underwent revision surgery were also excluded from the study.

Non-steroidal anti-inflammatory drugs (NSAIDs) and acetylsalicylic acid $\leq 100 \mathrm{mg}$ were suspended one week prior to surgery in all patients.

Operations were performed under either general, regional or combined general and regional anaesthesia, depending on the anaesthetic team's decision. All operations were performed by seven consultant orthopaedic surgeons working in a single orthopaedic department, using a direct lateral or Bauer's approach. All operations were performed without utilizing a cell saver or other retransfusion systems. Cefuroxime or clindamycin (in case of confirmed allergy to penicillin) were used as perioperative antibiotic prophylaxis. The intraoperative blood loss was recorded from the contents of the suction canister in the operating theatre. At the beginning of the observational study period (Study I), according to our institutional protocol, two closed suction drains were used for $24 \mathrm{hrs}$ postoperatively. After analysing the results of the initial period we decided to introduce blood conservation techniques to reduce our blood transfusion rate. Therefore during the second part of our observational study (Study II) only one intra-articular drain was used for a maximum of 24 hours. To quantify the volume of drainage, it was collected in calibrated and scaled bottles. The wound and drain sites were covered with the same sized Mepore ${ }^{\circledR}$ bandages after drain removal.

In terms of pain relief, paracetamol, tramadol and metamizole were administered as required. Physiotherapy was started on the first postoperative day with fully weight bearing on the operated lower limb, with restriction of adduction and external rotation.

During the observational study period the effect of the newly introduced medications (anticoagulants and antifibrinolytics) on thrombotic and bleeding complications were examined at our Department. Namely, the minor bleeding events and the major and clinically significant 
bleedings were recorded according to previous publications and guidelines [49, 76]. Our main focus was on perioperative blood loss and minor bleeding events, therefore more detailed information were collected in these topics such as bleeding and oozing through the surgical wound, area of skin haematoma and perioperative change in thigh volume.

\subsection{Thrombosis and thromboembolism}

Thromboembolic events were recorded when clinical signs emerged. In case of a suspected DVT (swelling, excessive oedema, discoloration of the limb or a positive Mayer's or Homans' sign) colour duplex sonography of the affected limb was performed. Clinical suspicion of PE meant an urgent need for computed tomography with pulmonary angiography according to our protocol.

During the first period, in Study I, 3 months after the intervention all of the patients were phoned and asked whether they had been diagnosed or treated with DVT or PE.

Later, during the second period, in Study II, the postoperative venous events were not routinely screened, but all clinically relevant events up to a minimum of 6 weeks after the operation were recorded.

\subsection{Major and clinically significant bleeding events}

Major bleeding was defined as fatal bleeding; overt bleeding associated with $\geq 20 \mathrm{~g} / \mathrm{L}$ fall in $\mathrm{Hb}$; overt bleeding leading to transfusion of $\geq 2$ units packed cells or whole blood; retroperitoneal, intracranial, intraocular or intraspinal bleeding; bleeding warranting treatment cessation or leading to reoperation.

Clinically significant bleeding events were defined as spontaneous skin haematoma $\geq 25 \mathrm{~cm}^{2}$, wound haematoma $\geq 100 \mathrm{~cm}^{2}$, spontaneous nose or gingival bleeding $>5 \mathrm{~min}$, spontaneous or intervention associated macroscopic haematuria lasting $>24 \mathrm{~h}$, and any other bleeding event considered clinically significant [49-51]. 


\subsection{Minor bleeding events}

Minor bleeding was defined as wound bleeding, serous wound discharge classified in four categories and wound haematoma smaller than $100 \mathrm{~cm}^{2}$ (Table 2 and 3).

\subsection{Bleeding through the surgical incision and serous wound discharge}

Definition of wound bleeding was the bleeding from the surgical wound into the dressing during the first postoperative 24 hours, until drain removal. Its intensity was categorized according to Table 2 .

Serous wound discharge was defined as the oozing of the surgical wound and drain site after drain removal. The duration of discharge was examined every day, its cessation was precisely documented. The intensity of serous wound discharge was observed as well. On the $3^{\text {rd }}$ and $7^{\text {th }}$ postoperative days its exact amount was documented according to the previously established categories (Table 2), when wound dressings were checked over the surgical incision and the drain site. Subgroup analysis was performed for the patients who were last on the operating list each day, because in these cases the earlier anticoagulation administration (shorter period between the wound closure and next dose of thromboprophylaxis) might cause increased amount of wound bleeding and prolonged discharge.

Table 2 Categories of wound bleeding (postoperative 0-24 h) and serous wound discharge (after drain removal):

\begin{tabular}{ll}
\hline $\mathbf{0}$ & Clean and dry wound dressing \\
$\mathbf{1}$ & Small spots but not wet through \\
$\mathbf{2}$ & A part of the wound dressing wet through during a day \\
$\mathbf{3}$ & The dressing wet through fully during a day, change and/or covering gauze were \\
& necessary \\
\hline
\end{tabular}

\subsection{Skin haematoma}

The area of skin haematoma (suffusion) was measured and patients were categorized according to our previously established criteria (Table 3, Figure 2). 
Table 3 Categories of haematoma:

\begin{tabular}{ll}
\hline $\mathbf{0}$ & none \\
$\mathbf{1}$ & $<100 \mathrm{~cm}^{2}$ \\
$\mathbf{2}$ & $100-200 \mathrm{~cm}^{2}$ \\
$\mathbf{3}$ & $200-300 \mathrm{~cm}^{2}$ \\
$\mathbf{4}$ & $300-400 \mathrm{~cm}^{2}$ \\
$\mathbf{5}$ & $400-500 \mathrm{~cm}^{2}$ \\
$\mathbf{6}$ & $500 \mathrm{~cm}^{2}<$ \\
\hline
\end{tabular}

\subsection{Change in thigh volume}

Excessive oozing might be associated with increased thigh volume after THR [77]. Jones and Pearson's anthropometric method objectively estimates leg volume by partitioning the leg into six segments which are similar to truncated cones [78]. The upper three of these segments were used to calculate the thigh volume (Figure 3 ). The measurements were carried out with the patient standing erect and the feet slightly apart. Four circumferences were taken with a metric tape at predetermined sites: 1) the gluteal furrow, 2) one-third of the subischial height up from the knee joint line, 3) the minimum circumference above the knee, 4) the maximum circumference around the knee. For each circumference, the heights above the floor level were measured by a stadiometer. Thigh volume (mL) was calculated by summing up the volumes of the three truncated cones. Thigh volumes were measured preoperatively and on the $7^{\text {th }}$ postoperative day.
Figure 2 Example for skin haematoma after THR from 6th category

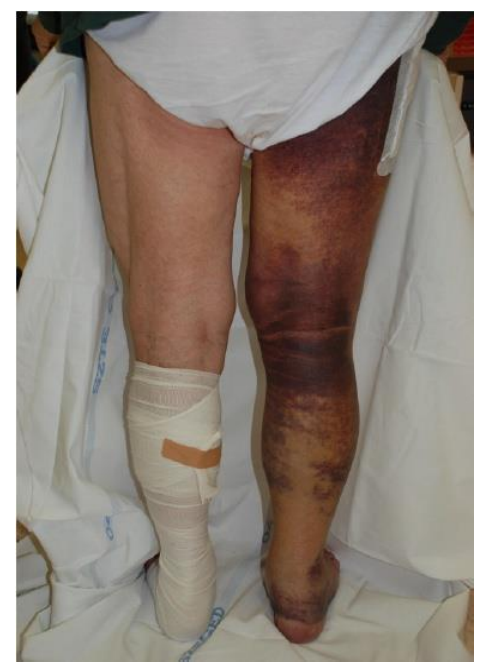

Figure 3 Measurement sites of circumferences for thigh volume calculation [78].

Explanation is in the text.

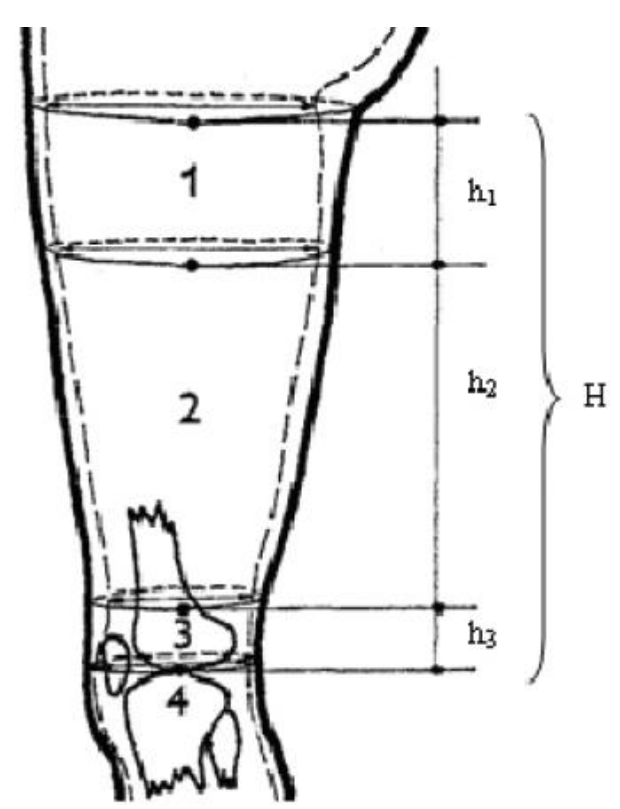




\subsection{Calculation of total perioperative blood loss}

Study I: The calculated perioperative blood loss (V, $\mathrm{mL})$ was compared between the two groups. For this purpose, the patient's height $(\mathrm{H}, \mathrm{cm})$, weight $(\mathrm{G}, \mathrm{kg})$ and haematocrit level preoperatively $\left(\mathrm{Hct}_{0}\right)$ and on the first postoperative day $\left(\mathrm{Hct}_{1}\right)$ were recorded. Patients, who got transfusion in the first $24 \mathrm{~h}$ after the operation, were excluded from this calculation. Nadler's formula was used for calculating the perioperative blood loss [79]:

$$
\mathrm{V}=\mathrm{EBV} \times \ln \left(\text { Hcto }_{\mathbf{0}} / \text { Hct }_{1}\right)
$$

Estimated blood volumes (EBV) were calculated with the following formula:

$$
\mathrm{EBV}=\mathrm{A} \times \mathrm{H}^{0,725} \times \mathbf{G}^{0,425}-\mathrm{B}
$$

where $\mathrm{A}=0.0236$ for men; $\mathrm{A}=0.0248$ for women; $\mathrm{B}=1.229$ for men; $\mathrm{B}=1.954$ for women.

Study II: During Study II, when the blood loss reducing effect of TXA was examined, a different calculation was used, which took into account postoperative haemodilution and transfusion requirement as well. The $\mathrm{Hb}$ and Hct levels were measured on the first, second and fifth day after the operation. The blood volume and haemodilution were assumed to normalize on the fifth day. The total perioperative blood loss was monitored as total drop in Hct level on postoperative fifth day compared to the preoperative Hct level. The patient's blood volume (PBV) was calculated using the Nadler's formula [79] as follows:

$$
\text { PBV }(\text { litres })=\left(\mathbf{k} 1 \times \text { height }^{3}(\mathrm{~m})\right)+(\mathbf{k} 2 \mathrm{x} \text { weight }(\mathrm{kg}))+\mathbf{k 3}
$$

where $\mathrm{k} 1=0.3669, \mathrm{k} 2=0.03219$ and $\mathrm{k} 3=0.6041$ for men, and $\mathrm{k} 1=0.3561, \mathrm{k} 2=0.03308$ and $\mathrm{k} 3=0.1833$ for women.

Multiplying the PBV by the haematocrit (Hct), gives the red blood cell (RBC) volume. Thus a change in the RBC volume can calculated from a change in the Hct level [80] as follows:

Total RBC volume loss $=$ PBV x $\left(\right.$ Hct $_{\text {pre-op }}-$ Hct $\left._{\text {post-op }}\right)$ 
The number of units of blood transfused during the hospital stay was recorded. Transfusion (mean volume per unit: $280 \mathrm{~mL}$, mean Hct per unit: 0.55) were taken into account by calculating the total blood loss as follows:

Total blood loss $($ litres $)=($ Total RBC volume loss $+($ Number of units transfused $x 0.28 x$

$$
\text { 0.55)) / ((Hct } \left.\left.\text { pre-op }+ \text { Hct }_{\text {post-op }}\right) / 2\right)
$$

\subsection{Treatment protocols}

Study I: We prospectively collected and reviewed all patients undergoing primary cemented THR for osteoarthritis or avascular necrosis of the femoral head from February 2011 until March 2012. These patients were divided into two groups to receive either LMWH enoxaparin (Clexane ${ }^{\circledR}$, Sanofi-Aventis) or the oral direct thrombin inhibitor dabigatran etexilate (Pradaxa ${ }^{\circledR}$, Boehringer Ingelheim International). Patients were enrolled in each group according to our weekly altered medication supply: every odd week enoxaparin and every even week dabigatran was administered. Our study thus can be called a quasi randomised study. Anticoagulants were administered according to the current orthopaedic and manufacturer guidelines $[11,19,27,81]$. In the enoxaparin group, $40 \mathrm{mg}$ enoxaparin was given subcutaneously 12 hours before operation and at $8 \mathrm{pm}$ for the next 28-35 days postoperatively. In the dabigatran group, dabigatran etexilate $220 \mathrm{mg}$ was administered for patients below 75 years of age and $150 \mathrm{mg}$ for patients over 75 years of age. Administration was started 4 hours postoperatively with a half-dose $(110 \mathrm{mg}$ or $75 \mathrm{mg}$ ) and then the full dose was administered once a day at 8 am for 28-35 days after replacement $[7,11,81,82]$.

Study II: Tranexamic acid was introduced in our Department at the end of 2013, after successful trials in both elective and trauma surgery, as a perioperative potentially bloodconserving adjunct during primary lower limb arthroplasty. Consecutive patients undergoing primary cemented THR were studied prospectively. Patients received TXA perioperatively between January 2014 and November 2014 designated as TXA group. We compared this data to a group of patients who underwent the same procedure, between February 2012 and December 2012 (control group), before the introduction of TXA. All patient data in each 
observational period was prospectively collected, reviewed and all patients received a primary cemented THR for osteoarthritis or avascular necrosis of the femoral head. In both groups 10 mg rivaroxaban (Xarelto ${ }^{\circledR}$, Bayer Schering Pharma) was administered as perioperative thromboprophylaxis, started 6 hours postoperatively, then once a day at 8 pm for 28-35 days after joint replacement surgery according to the current orthopaedic and manufacturer guidelines [7, 11, 24].

\subsection{Statistical analysis}

In Study I, the statistical analysis was done using t-test, chi-square test and ANOVA with StatSoft ${ }^{\circledR}$ Statistica v.9 statistical software.

In Study II SPSS Statistics 16.0 software was used for statistical analysis. Normal distribution of the data was analysed by the Shapiro-Wilk test. Parametric (Student's T-test) and non-parametric (Mann-Whitney U-test) tests were used for the comparative analyses of data with normal and non-normal distribution, respectively. Categorical variables were analysed by the Chi-square method, with the use of Fischer's exact test, when appropriate.

Results and data are presented in the text as mean ( \pm standard deviation (SD)) or median (interquartile range). The p-values below 0.05 were regarded as statistically significant.

\subsection{Ethical approval}

Clinical ethics committee approved this study and informed consent was obtained from each participant. 


\section{Results}

\section{Study I:}

122 patients were enrolled, 61 into each group. The number and descriptive data of the patients are presented in Table 4. Characteristics of patients were similar, without no significant differences.

Table 4 Patient characteristics $\pm S D$ (min-max)

\begin{tabular}{lll}
\hline & Enoxaparin & Dabigatran \\
\hline Number of patients & 61 & 61 \\
Gender & $16 \AA / 45 \bigcirc$ & $17 \AA / 44 \uparrow$ \\
Average age & $69 \pm 9.7(47-85)$ & $69 \pm 7.6(52-86)$ \\
Height (cm) & $164 \pm 8.9(150-189)$ & $164 \pm 8.0(148-186)$ \\
Weight (kg) & $77 \pm 14.1(45-100)$ & $76 \pm 11.6(48-99)$ \\
BMI (kg/m $)$ & $28.5 \pm 4.8(19.1-37.7)$ & $28.3 \pm 4.3(17.9-40.9)$ \\
Estimated blood volume (mL) & $4464 \pm 743.8(2775-6241)$ & $4458 \pm 637.9(2859-5893)$ \\
Haematocrit before surgery & $0.40 \pm 0.038(0.30-0.50)$ & $0.40 \pm 0.038(0.31-0.50)$ \\
Haemoglobin before surgery $(\mathbf{g} / \mathbf{L})$ & $134.7 \pm 15.7(94-176)$ & $135.9 \pm 13.5(101-172)$ \\
Duration of surgery (min) & $77 \pm 18.8(50-140)$ & $74 \pm 15.8(50-120)$ \\
Anaesthesia & $16 / 38 / 7$ & $16 / 37 / 8$ \\
general/regional/combination & & \\
\hline
\end{tabular}

No patients developed clinical features of DVT during the treatment and follow-up period, therefore duplex sonography was not performed. No PE events or deaths occurred during the hospitalization and within 3 months after the operation.

There were no significant differences between the two groups in major bleeding events (Table 5). 22 patients in the dabigatran group and 21 patients in the enoxaparin group needed transfusion in the postoperative period. 
Table 5 Significant bleeding complication in our study according to guidelines of previous publications. Data are shown as number of events, percentage in brackets (\%).

\begin{tabular}{lll}
\hline & $\begin{array}{l}\text { Enoxaparin } \\
(\mathbf{n = 6 1 )}\end{array}$ & $\begin{array}{l}\text { Dabigatran } \\
(\mathbf{n = 6 1})\end{array}$ \\
\hline $\begin{array}{l}\text { Clinically overt bleeding leading to transfusion of } \\
\geq 2 \text { units packed cells }\end{array}$ & $4(6.6)$ & $5(8.2)$ \\
Wound haematoma $\geq 100 \mathrm{~cm}^{2}$ & $29(47.5)$ & $33(54.1)$ \\
$\begin{array}{l}\text { Intervention associated macroscopic haematuria } \\
\text { lasting }>24 \mathrm{~h}\end{array}$ & $0(0.0)$ & $1(1.6)$ \\
\hline
\end{tabular}

No significant differences were found between the two groups in volume of blood loss during surgery: $300 \mathrm{ml}( \pm 137.23)$ in dabigatran group and $314 \mathrm{ml}( \pm 197.32)$ in the enoxaparin group was measured. Volume of the postoperative drainage also did not differ significantly: $470.82 \mathrm{ml}( \pm 276.85)$ in dabigatran group and $471.64 \mathrm{ml}( \pm 253.3)$ in enoxaparin group was found. There were no significant differences in perioperative calculated blood loss, which were $1072.4 \mathrm{ml}( \pm 586.6)$ in the dabigatran group and $1152.3 \mathrm{ml}( \pm 486)$ in the enoxaparin group. Subgroup analysis did not show any significant differences in wound bleeding/discharging and drainage volume regarding to patient's position on the operating schedule (first or last on the list). No significant differences were found in the total blood loss as calculated by a total drop in preoperative and postoperative first day Hb level: $30.7 \mathrm{~g} / \mathrm{L}( \pm 13.5)$ using dabigatran and 28.3 $\mathrm{g} / \mathrm{L}( \pm 12.7)$ using enoxaparin. 8 patients from the enoxaparin group and 3 patients from the dabigatran group received transfusion in the first $24 \mathrm{~h}$ after their operations, therefore they were excluded from this calculation and comparison of postoperative Hb drops.

Wound bleeding also did not show significant differences between the two groups (Table $6)$.

Table 6 Wound bleeding incidences in the two groups. Data are shown as number of events, percentage in brackets (\%). Definitions of categories are found in Table 2.

\begin{tabular}{lllll}
\hline Category: & $\mathbf{0}$ & $\mathbf{1}$ & $\mathbf{2}$ & $\mathbf{3}$ \\
\hline Enoxaparin $(\mathrm{n}=61)$ & 2 & 24 & 16 & 19 \\
& $(3.3)$ & $(39.3)$ & $(26.2)$ & $(31.2)$ \\
Dabigatran $(\mathrm{n}=61)$ & 1 & 23 & 18 & 19 \\
& $(1.6)$ & $(37.7)$ & $(29.5)$ & $(31.2)$ \\
\hline
\end{tabular}


Data on haematoma frequency is presented in Table 7. There was no statistical significance between groups.

Table 7 Haematoma frequency. Data are shown as number of events, percentage in brackets (\%). Definitions of categories are found in Table 3.

\begin{tabular}{llllllll}
\hline Category: & $\mathbf{0}$ & $\mathbf{1}$ & $\mathbf{2}$ & $\mathbf{3}$ & $\mathbf{4}$ & $\mathbf{5}$ & $\mathbf{6}$ \\
\hline \multirow{2}{*}{ Enoxaparin $(\mathrm{n}=61)$} & 23 & 9 & 6 & 10 & 4 & 2 & 7 \\
& $(37.7)$ & $(14.8)$ & $(9.8)$ & $(16.4)$ & $(6.6)$ & $(3.3)$ & $(11.4)$ \\
Dabigatran $(\mathrm{n}=61)$ & 22 & 6 & 15 & 6 & 5 & 5 & 2 \\
& $(36.1)$ & $(9.8)$ & $(24.6)$ & $(9.8)$ & $(8.2)$ & $(8.2)$ & $(3.3)$ \\
\hline
\end{tabular}

Significant increases of thigh volumes were observed in both groups on the $7^{\text {th }}$ postoperative day compared to preoperative volumes, however, no significant difference was found between the two groups (Figure 4).

Figure 4 Postoperative thigh volume increase. A significant increase (\#) of thigh volume on the 7th postoperative day were found in both groups compared to preoperative volumes, however, no significant difference was found between the two groups ( $p<0.05)$.

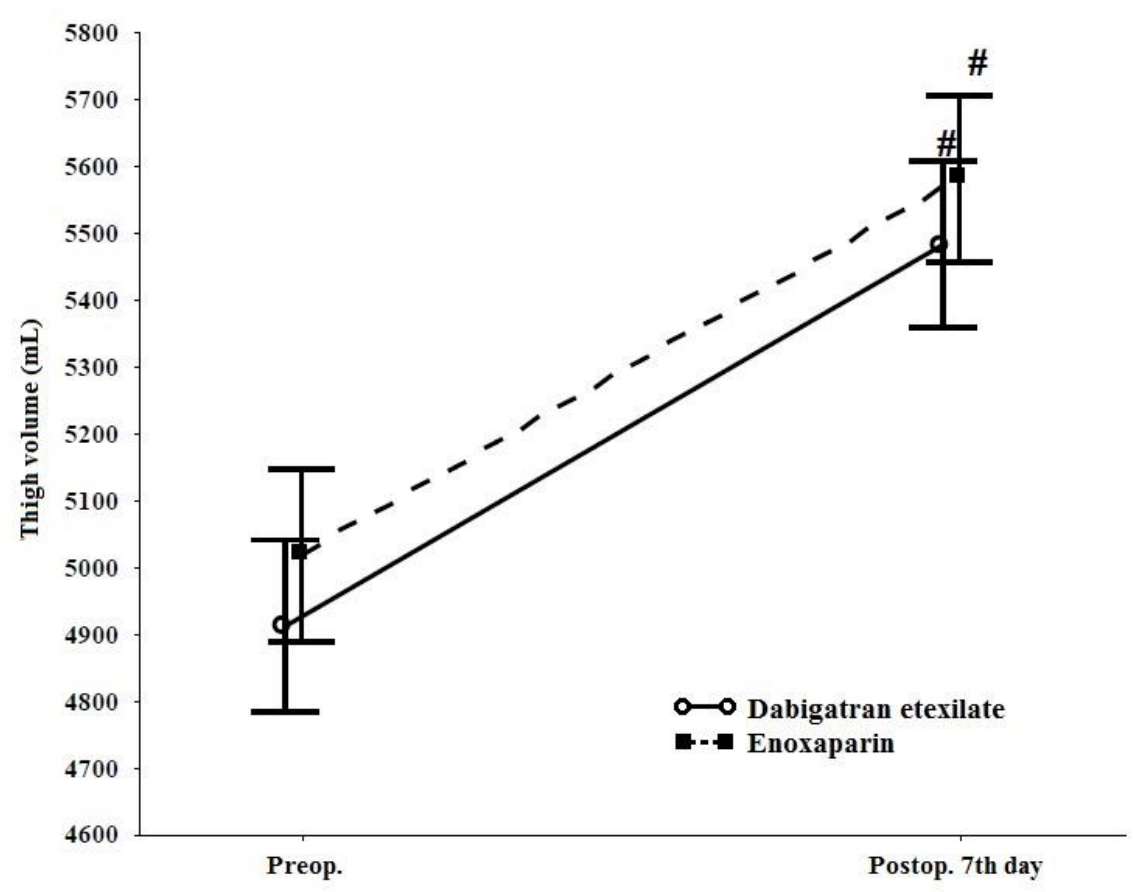


In contrast to these, the main differences between the two groups are in the duration and intensity of serous wound discharge. Duration of wound discharge was $2.2( \pm 2.7)$ days in the dabigatran group and $1.2( \pm 1.9)$ days in the enoxaparin group after drain removal $(p<0.05)$ (Figure 5). Significantly higher intensity of wound draining was found in the dabigatran group $(\mathrm{p}<0.05)$ (Table 8 and Figure 6).

Figure 5 Duration of drain wound oozing in days. * means significant difference between the two groups $(p<0.05)$. Duration of serous wound discharge was 2.2 ( \pm 2.7$)$ days in the dabigatran group and $1.2( \pm 1.9)$ days in the enoxaparin group.

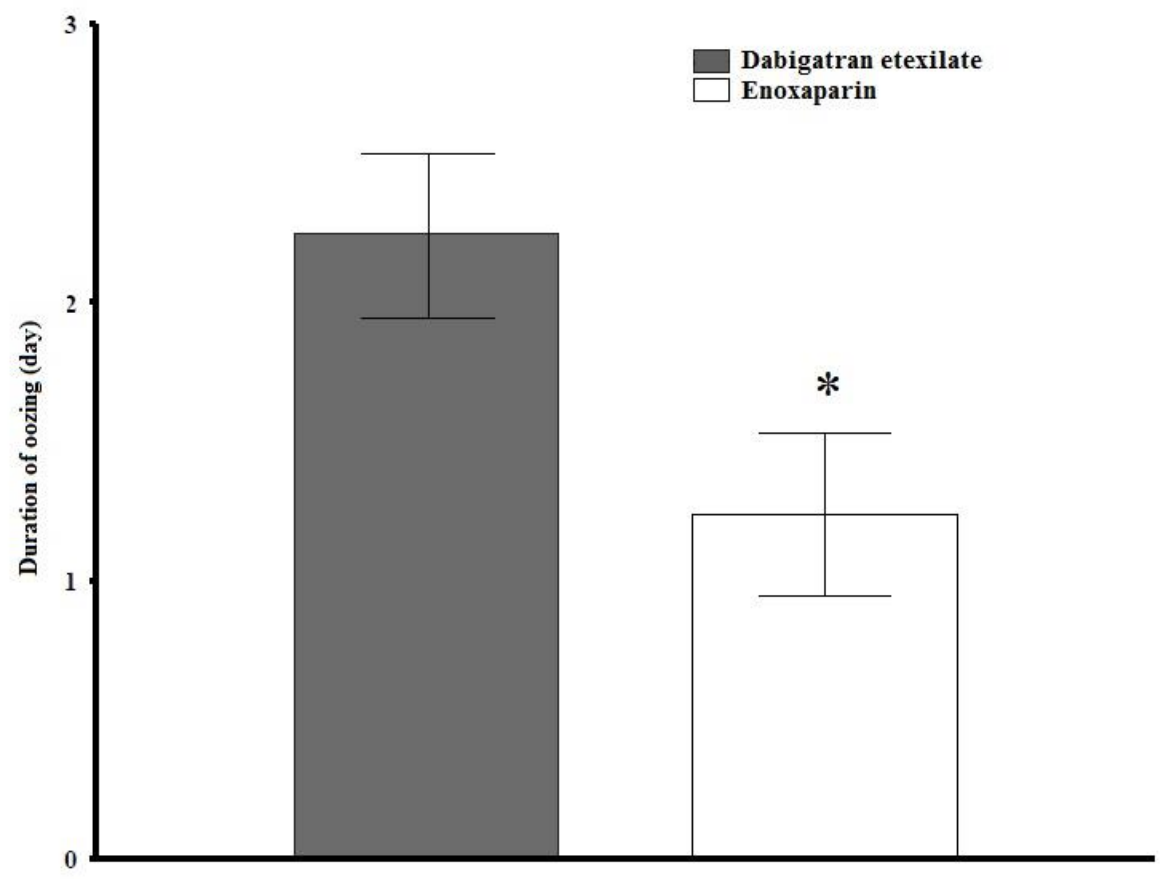

Table 8 Number of patients with different categories of serous wound discharge. Data are shown as number of events, percentage in brackets (\%). Definitions of categories are found in Table 2.

\begin{tabular}{|c|c|c|c|c|c|c|c|c|}
\hline \multirow[b]{2}{*}{ Category: } & \multicolumn{4}{|l|}{ Day 3} & \multicolumn{4}{|l|}{ Day 7} \\
\hline & All & 1 & 2 & 3 & All & 1 & 2 & 3 \\
\hline Enoxaparin $(n=61)$ & $\begin{array}{l}13 \\
(21.3)\end{array}$ & $\begin{array}{l}5 \\
(8.2)\end{array}$ & $\begin{array}{l}2 \\
(3.3)\end{array}$ & $\begin{array}{l}6 \\
(9.8)\end{array}$ & $\begin{array}{l}3 \\
(4.9)\end{array}$ & $\begin{array}{l}2 \\
(3.3)\end{array}$ & $0(0)$ & $\begin{array}{l}1 \\
(1.6)\end{array}$ \\
\hline Dabigatran $(n=61)$ & $\begin{array}{l}23 \\
(37.7)\end{array}$ & $\begin{array}{l}7 \\
(11.4)\end{array}$ & $\begin{array}{l}2 \\
(3.3)\end{array}$ & $\begin{array}{l}14 \\
(23.0)\end{array}$ & $\begin{array}{l}10 \\
(16.4)\end{array}$ & $\begin{array}{l}3 \\
(4.9)\end{array}$ & $\begin{array}{l}3 \\
(4.9)\end{array}$ & $\begin{array}{l}4 \\
(6.6)\end{array}$ \\
\hline
\end{tabular}


Figure 6 Intensity of serous wound discharge. (*) Significantly higher serous wound discharge was found in the dabigatran group on the $3^{\text {rd }}$ and $7^{\text {th }}$ postoperative days. (\#) Significant decrease in serous wound discharge was measured in both groups between $3^{\text {rd }}$ and $7^{\text {th }}$ postoperative days.

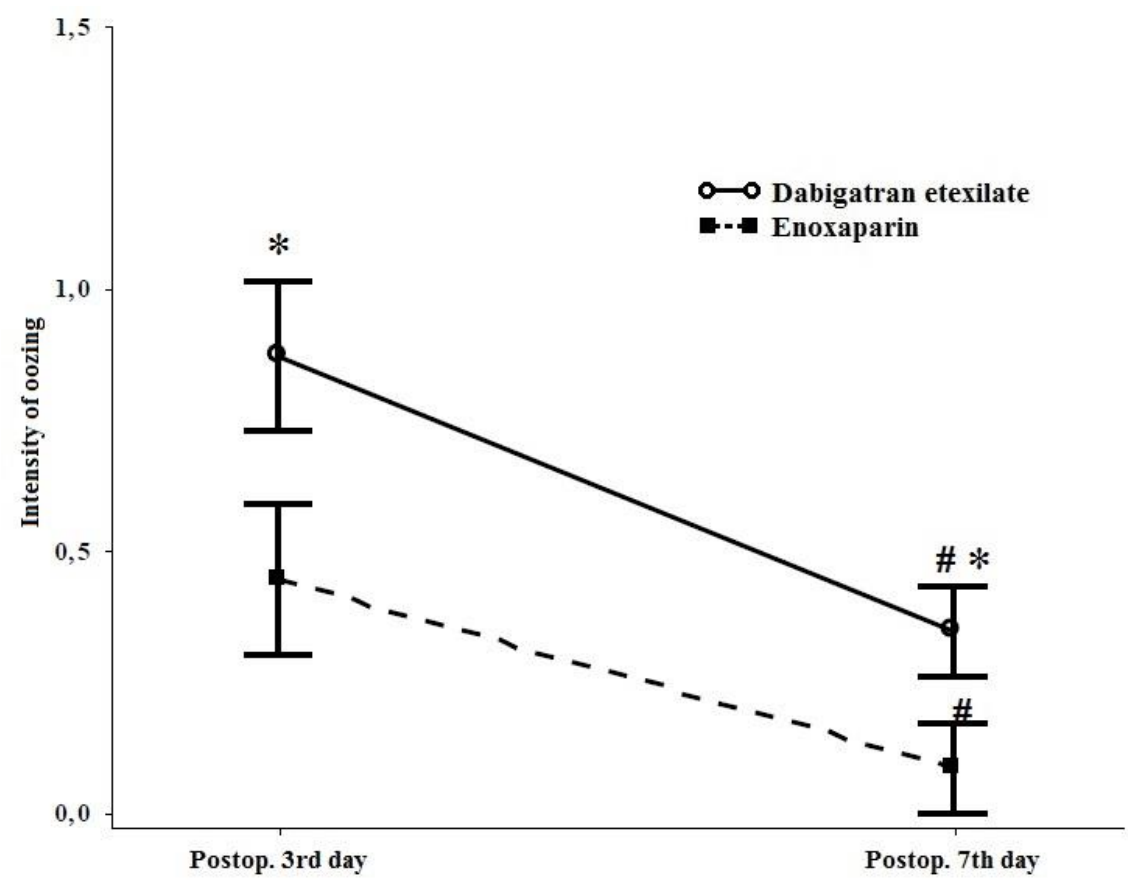

\section{Study II:}

81 patients were enrolled into the TXA group, who met our inclusion criteria and got perioperative tranexamic acid. They were compared with 87 patients in the control group. Our study population's basic demographic, laboratory and surgical data is presented in Table 9. The two groups were statistically identical in terms of patient characteristics. 
Table 9 Patient characteristics $\pm S D$ (min-max)

\begin{tabular}{|c|c|c|}
\hline & TXA group & Control group \\
\hline Number of patients & 81 & 87 \\
\hline Gender & $18 \diamond^{\lambda} / 63 \uparrow$ & $21 \lesssim / 66$ q \\
\hline Average age & $68 \pm 6.7(46-81)$ & $69 \pm 8.2(49-85)$ \\
\hline Height (cm) & $163 \pm 9.1(140-195)$ & $163 \pm 7.9(148-180)$ \\
\hline Weight (kg) & $76.2 \pm 12.4(45-100)$ & $74.5 \pm 11.5(54-100)$ \\
\hline BMI $\left(\mathrm{kg} / \mathrm{m}^{2}\right)$ & $28.5 \pm 3.8(19.9-36.4)$ & $28 \pm 3.7(21.6-38.5)$ \\
\hline Preoperative thigh volume $(\mathrm{mL})$ & $5194 \pm 1129(3153-7588)$ & $4868 \pm 1002(2882-8210)$ \\
\hline Patients' blood volume (L) & $4.411 \pm 0.711(2540-6210)$ & $4.353 \pm 0.660(3260-5800)$ \\
\hline Haematocrit before surgery & $0.40 \pm 0.038(0.30-0.50)$ & $0.41 \pm 0.040(0.30-0.48)$ \\
\hline Duration of surgery (min) & $75 \pm 20.9(30-130)$ & $77 \pm 16.8(42-150)$ \\
\hline $\begin{array}{l}\text { Anaesthesia } \\
\text { general/regional/combination }\end{array}$ & $13 / 56 / 12$ & $16 / 61 / 10$ \\
\hline
\end{tabular}

Three patients in the control group developed clinical features of DVT during their hospital stay, however, colour duplex sonography did not prove our clinical suspicion. No VTE events or deaths were recorded during the study and within the investigated postoperative six week period.

There was no difference in intraoperative blood loss between the two groups: $306.4 \mathrm{~mL}$ $( \pm 126.6 \mathrm{~mL})$ in the TXA group and $316.7 \mathrm{~mL}( \pm 170.5 \mathrm{~mL})$ in the control group $(\mathrm{p}=0.957)$; however, the postoperative drainage differed significantly: $280 \mathrm{~mL}(170-350 \mathrm{~mL})$ in the TXA group and $400 \mathrm{~mL}(300-550 \mathrm{~mL})$ in the control group $(\mathrm{p}<0.001)$. The median calculated perioperative blood loss was significantly lower in the TXA group compared to the control group (p<0.001): $1150 \mathrm{~mL}(780-1496 \mathrm{~mL})$ and $1579 \mathrm{~mL}(1313-2074 \mathrm{~mL})$, respectively (Figure 7). 12 (15\%) patients in the TXA group and 34 (39\%) patients in the control group needed transfusion after the operation. The total number of transfused RBC units in the TXA group was 26 versus 82 units in the control group. The mean transfusion rate was significantly lower among the patients where perioperative tranexamic acid was used ( 0.32 unit ( \pm 0.09 unit) versus 0.94 unit ( \pm 0.15 unit), $\mathrm{p}=0.003$ ). The intensity of surgical wound bleeding differed significantly between the two groups during the first postoperative 24 hours: $1.71( \pm 0.083)$ in 
the control group versus $0.35( \pm 0.086)$ in the TXA group $(\mathrm{p}<0.001)$. The number of patients in the different wound bleeding categories in both groups are illustrated in Table 10.

Table 10 Frequency chart of wound bleeding intensity. The intensity of wound bleeding in the postoperative 24 hours was significantly lower in the TXA group $(p<0.001)$ compared to control group. Data are presented as number of patients and relative percentages in bracket. Definitions of categories are detailed in Table 2.

\begin{tabular}{lll}
\hline Category: & $\begin{array}{l}\text { TXA group } \\
(\mathbf{n = 8 1})\end{array}$ & $\begin{array}{l}\text { Control } \\
\text { group } \\
(\mathbf{n = 8 8 7})\end{array}$ \\
\hline $\mathbf{0}$ & $64(79.0 \%)$ & $1(1.1 \%)$ \\
$\mathbf{1}$ & $10(12.3 \%)$ & $39(44.8 \%)$ \\
$\mathbf{2}$ & $3(3.7 \%)$ & $31(35.6 \%)$ \\
$\mathbf{3}$ & $4(4.9 \%)$ & $16(18.4 \%)$ \\
\hline
\end{tabular}

Figure 7 Calculated total blood loss. Significantly lower blood loss was seen in the TXA group $(p<0.001)$.

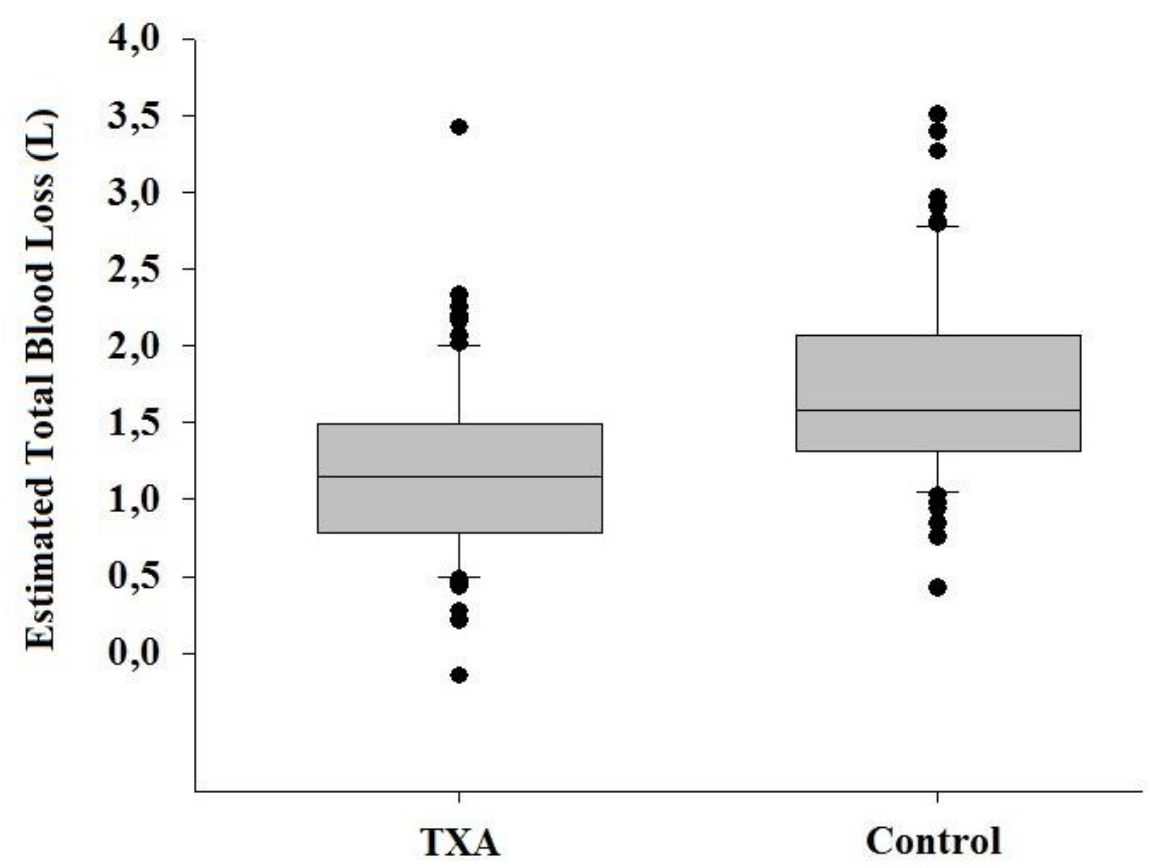

The extent of postoperative thigh swelling showed significant difference on the $7^{\text {th }}$ postoperative day: $270.3 \mathrm{~mL}(129.1-449.0 \mathrm{~mL})$ in the TXA group and $539.8 \mathrm{~mL}(350.0-864.8$ 
$\mathrm{mL}$ ) in the control group ( $\mathrm{p}<0.001)$ (Figure 8). The area of haematoma was significantly smaller in the TXA group $(0.64( \pm 0.21)$ vs. $2.46( \pm 2.13), p<0.001)$. The duration of serous wound discharge after drain removal had a tendency to be shorter in the TXA group ( 0.56 day $( \pm 0.97$ day)) compared to the control group (1.15 day ( \pm 1.86 day), which did not reach the statistical significance $(\mathrm{p}=0.064)$.

Figure 8 Postoperative change in thigh volume. Significant thigh volume increase was found in the control group on the $7^{\text {th }}$ postoperative day $(p<0.001)$.

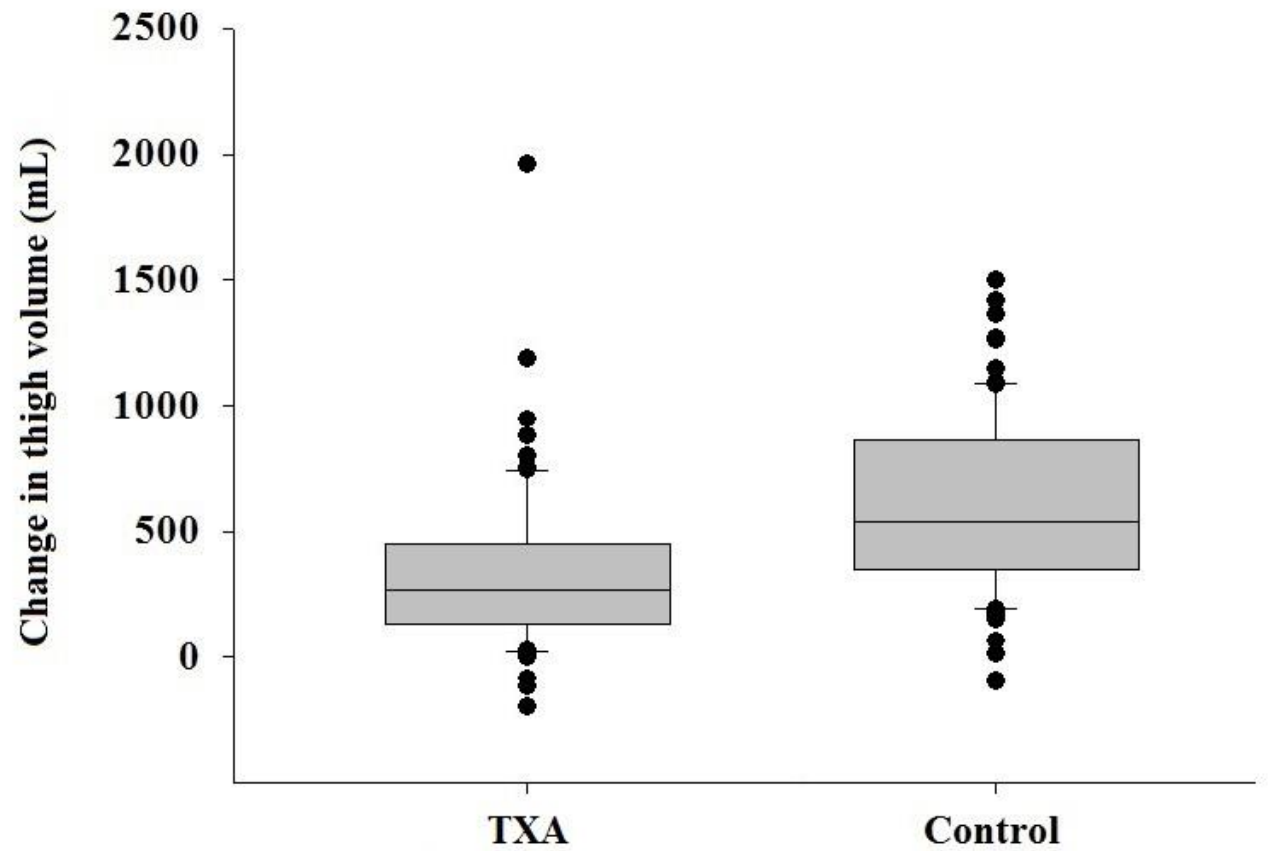




\section{Discussion}

\section{Study I:}

Without any prophylaxis the incidence of DVT ranges from $40 \%$ to $60 \%$ in patients after major orthopaedic operations $[4,5]$ and the incidence of fatal PE is $2 \%$ to $3 \%$ after elective hip replacement $[6,7]$. Despite decades of clinical experience and a plethora of studies, the ideal method of VTE prophylaxis remains controversial. Thromboprophylaxis reduces the risk of VTE (including fatal PE) by more than $60 \%$ [24].

During the last few decades, based on clinical trials, experiences and guidelines, LMWHs have become the standard thromboprophylactic drugs in orthopaedics [36]. Enoxaparin, is still one of the most favoured subcutaneously administered antithrombotic agent in Europe, thus logically it was used as the comparator during clinical trials with dabigatran etexilate. Trials with the new direct thrombin inhibitor investigated the major and clinically significant bleeding events as safety endpoints, however, minor bleeding events were mostly ignored and their exact details were unknown [49-52]. Table 11 shows collected bleeding complications of the relevant doses in the studies with dabigatran etexilate.

The BISTRO I determined the safe therapeutic range of dabigatran etexilate following THR [52]. At the end of this study the lack of any major bleeding episodes and potentially higher number of minor bleeding events were explained by the inaccurately defined bleeding complication criteria.

Different doses of dabigatran were compared during BISTRO II study [49]. The higher doses of dabigatran were significantly more effective than enoxaparin, although also resulted in increased bleeding events.

The RE-NOVATE study declared that $150 \mathrm{mg}$ or $220 \mathrm{mg}$ doses of dabigatran etexilate are as effective as $40 \mathrm{mg}$ enoxaparin for the prevention of venous thromboembolism, with a similar safety profile [50].

RE-NOVATE II study found similar risk of bleeding and safety profiles in the $220 \mathrm{mg}$ dabigatran etexilate group and the $40 \mathrm{mg}$ enoxaparin groups after THR [51]. Minor and clinically relevant non-major bleeding was highlighted in this study, as summarized results, which showed a raised incidence of minor wound complications using dabigatran etexilate. 
Table 11 Comparable bleeding events during the treatment periods of each study. Data are $n(\%)$. *For all bleeding outcomes, none of the differences between each dabigatran etexilate dose and enoxaparin were significant. +Starting with a half dose 1-4 hours postoperatively. \#Starting the evening before surgery. bid, twice daily; qd, once daily; n.a. means not applicable.

\begin{tabular}{|c|c|c|c|c|}
\hline Studies & $\begin{array}{l}\text { Total } \\
\text { population }\end{array}$ & $\begin{array}{l}\text { Major } \\
\text { bleeding } \\
\text { events }\end{array}$ & $\begin{array}{l}\text { Clinically } \\
\text { significant } \\
\text { bleeding } \\
\text { events }\end{array}$ & $\begin{array}{l}\text { Minor } \\
\text { bleeding } \\
\text { events }\end{array}$ \\
\hline \multicolumn{5}{|l|}{ BISTRO I } \\
\hline Dabigatran $50 \mathrm{mg}$ bid & 30 & 0 & n.a. & $2(7.4 \%)$ \\
\hline Dabigatran $150 \mathrm{mg}$ bid & 29 & 0 & n.a. & $26(89.7 \%)$ \\
\hline Dabigatran $300 \mathrm{mg}$ qd & 46 & 0 & n.a. & $41(89.1 \%)$ \\
\hline \multicolumn{5}{|l|}{ BISTRO II } \\
\hline Dabigatran $50 \mathrm{mg}$ bid & 265 & 0 & $5(1.9 \%)$ & $11(4.2 \%)$ \\
\hline Dabigatran $150 \mathrm{mg}$ bid & 266 & $10(3.8 \%)$ & $11(4.1 \%)$ & $23(8.6 \%)$ \\
\hline Dabigatran $300 \mathrm{mg}$ bid & 258 & $12(4.7 \%)$ & $12(4.7 \%)$ & $22(8.5 \%)$ \\
\hline Enoxaparin $40 \mathrm{mg} \mathrm{qd} \mathrm{\#}$ & 270 & $6(2.2 \%)$ & $7(2.6 \%)$ & $14(5.2 \%)$ \\
\hline \multicolumn{5}{|l|}{ RE-NOVATE } \\
\hline Dabigatran $220 \mathrm{mg} \mathrm{qd}{ }^{*}+$ & 1146 & $23(2.0 \%)$ & $48(4.2 \%)$ & $70(6.1 \%)$ \\
\hline Dabigatran $150 \mathrm{mg} \mathrm{qd}^{*}+$ & 1163 & $15(1.3 \%)$ & $55(4.7 \%)$ & $72(6.2 \%)$ \\
\hline Enoxaparin $40 \mathrm{mg} \mathrm{qd} \mathrm{\#}$ & 1154 & $18(1.6 \%)$ & $40(3.5 \%)$ & $74(6.4 \%)$ \\
\hline \multicolumn{5}{|l|}{ RE-NOVATE II } \\
\hline Dabigatran $220 \mathrm{mg} \mathrm{qd}^{*}+$ & 1010 & $14(1.4 \%)$ & $23(2.3 \%)$ & $61(6.0 \%)$ \\
\hline Enoxaparin $40 \mathrm{mg} \mathrm{qd} \mathrm{\#}$ & 1003 & $9(0.9 \%)$ & $20(2.0 \%)$ & $54(5.4 \%)$ \\
\hline
\end{tabular}

Enoxaparin exhibits predictable anticoagulation and can be given at fixed doses, but subcutaneous administration limits its use in the outpatient setting. Disadvantages include an indirect method of action, risk of HIT, allergic reactions due to its animal origin and a short elimination half-life [83]. If necessary, the possibility of monitoring the thrombocyte count and the efficacy through the aPTT exist and administration of protamine sulphate is available as an antidote $[7,84]$.

Dabigatran etexilate is just as effective and safe as LMWHs, furthermore it does not have the above mentioned disadvantages. However, it lacks the option of monitoring $[7,84,85]$. In 2016 idarucizumab was announced as a specific antidote for the immediate reversal of dabigatran. It is indicated when rapid reversal of the anticoagulant effects of dabigatran etexilate is required for emergency surgery/urgent procedure or life-threatening or uncontrolled bleeding [86]. 
Our clinical experiences with elevated serous wound discharge enticed us to explore the background of the bleeding profile of dabigatran focusing on minor bleeding events and design a study to prove our clinical observations. No previous similar detailed reports are available with dabigatran on the minor, but clinically important, potentially detrimental side effects of haematoma around the operated area (oozing from the wound and prolonged discharge from the drain site). A previous study in the United Kingdom found a significant, delayed wound discharges after taking dabigatran postoperatively. Based on their study they no longer administer dabigatran from the day of surgery but prefer to start the VTE prophylaxis with dalteparin (LMWH) until the wound is dry postoperatively and then discharge the patient home on oral dabigatran [72].

In our study the incidence of major and clinically significant bleeding events were higher in both groups compare to the dabigatran development trials [49-52], although the same previous guidelines were applied. Patients were equally divided and operated by seven experienced orthopaedic surgeons using the same surgical technique. No significant differences were seen in terms of individual complication rates amongst the surgeons.

Although our study involved a relatively small number of patients, we have managed to find significant differences in serous wound discharge. No such differences were found in terms of skin haematoma formation. Only a few studies examined the wound complication rate using dabigatran, our study was among the first ones [72, 87-89]. Our aim was not to establish the pharmacological explanation for minor bleeding complications. We can only hypothesise that the relatively early postoperative administration of dabigatran (starting with a half dose 1-4 hours after surgery), might be responsible for the increased incidence of postoperative wound ooze. The current ACCP guidelines recommend to start LMWH as thromboprophylaxis either $12 \mathrm{hrs}$ or more preoperatively or $12 \mathrm{hrs}$ or even later postoperatively rather than within $4 \mathrm{hrs}$ or less preoperatively or 4 hrs or less postoperatively [7, 27]. Also there are publications about an elevated incidence of bleeding complications and wound infection using rivaroxaban $[13,73]$.

We found the same, statistically significant increase in thigh volume in both our groups between the initial and $7^{\text {th }}$ postoperative day data, without any difference in thigh volumes with the two different anticoagulants. These increased thigh volumes might be caused by the normal wound healing processes which are regulated by local proinflammatory cytokines, growth 
factors, tissue response processes and are also related to the hidden blood loss that might be present during major orthopaedic interventions. A recent study examined histologically the effect of enoxaparin, rivaroxaban and dabigatran on wound healing process using a rat model, and found neither beneficial nor harmful effect of them on wound healing [90].

An early study in 1981 mentioned anticoagulant therapy causing wound haematoma and wound draining as risk factor of deep infection after THR [91]. It is still controversial whether a wound leakage can be an important source of late periprosthetic infection [91, 92], however some authors observed positive correlation between discharge from the wound and late deep infection [93, 94]. The first report on minor, but clinically important side-effects found an increased incidence of bruising and prolonged discharge from the drain site after enoxaparin compared to control group without thromboprophylaxis [95]. The "clexane-knee" entity was well known over the early introductory period of enoxaparin. Minor bleeding complications caused reluctance in the use of LMWHs at that time [96]. A questionnaire based study of hip and knee surgeons found in 1997 that $48 \%$ of surgeons had stopped using LMWHs because of bruising, ooze, bleeding problems and formation of haematoma [97]. Over the last two decades we have come to accept the minor side-effects of enoxaparin. The new dabigatran etexilate can potentially cause more prolonged oozing from the drain site and an increased incidence of serous wound discharge, which might prevent this agent from being widely used in orthopaedic surgery. Additional to this, it is unsafe to discharge a patient with an oozing wound or drain site, even when his/her postoperative state would otherwise allow this, which might lead to longer hospitalisation and prolonged use of antibiotics to prevent secondary contamination of the surgical site. This might increase the costs of perioperative care $[98,99]$.

Our first study has several strengths and weaknesses. It was performed in a single large volume tertiary referral university department, using consecutive patients, and a standardized surgical technique. The two compared groups were found to be demographically similar. Perioperative blood loss was monitored comprehensively (in theatre, calibrated drain canisters, $\mathrm{Hb}$ concentration, thigh volume monitoring, wound haematoma, drainage, serous discharge). Arguably our patient population is still relatively small, as establishing differences in reoperation or infection rate requires large multi-centre studies. We did use drains in primary THR patients, in both groups, which is although not unheard of, is relatively less common nowadays [100, 101]. The use of suction drains remains controversial after joint arthroplasty. 
There is increasing evidence suggesting that drains are not routinely required as they do not have any proven positive effect [102-104]. Based on our findings and these publications we started to reduce the number of drains (Study II) and currently we seldom use suction drains after THR.

\section{Study II:}

A handful of studies have examined peri- and postoperative bleeding after cemented THR with the use of tranexamic acid $[65,74,105,106]$. Regarding cemented THR, the femoral canal and the acetabular bony beds are closed off by bone cement, and its pressurization has a ceasing effect on blood loss from the intramedullary circulation. Therefore, postoperative bleeding tends to be lower in cemented THR compared to cementless THR, which means that it is essential to examine the two types of prosthesis separately [107]. Our study was amongst the first few orthopaedic studies publishing results on the effect of TXA following THR when the new oral anticoagulant rivaroxaban was used for thromboprophylaxis [75, 108]. According to our knowledge, this study was the first prospective study examining the effect of TXA in primary cemented THR using rivaroxaban as thromboprohylaxis and focusing on minor bleeding and wound leakage complications.

Regarding cemented THR, the timing and dosage of TXA are still subject to an intense debate [63]. Previous studies used TXA in patients undergoing THR with doses of 10 or 15 $\mathrm{mg} / \mathrm{kg}$ with or without continuous infusion or in the form of a single $1 \mathrm{~g}$ bolus before surgery, and reported significantly lower amounts of blood loss both intra- and postoperatively [64-66, $74,106,109,110] .10 \mathrm{mg} / \mathrm{kg}$ TXA before the incision was considered to produce a therapeutic blood concentration of $5 \mathrm{mg} / \mathrm{L}$ to $10 \mathrm{mg} / \mathrm{L}$ for three hours [106], which theoretically can reduce bleeding during surgery. The pharmacological effect of TXA is to delay fibrinolysis by blocking the lysine binding sites on the plasminogen molecule [65]. Theoretically, TXA has no influence on primary haemostasis and coagulation [111]. Other factors that affect intraoperative bleeding during THR may be related to the patient's comorbidities, the surgeons' commitment to intraoperative bleeding control, operating time and the method of anaesthesia [111]. With the respect to the timing of administration of TXA, Benoni et al. initially administered it at the end of the operation and then again 3 hours later, and could not find significant reduction of periand postoperative blood loss [105]. In contrast, Ekbäck at al. reported that TXA initially given 
just before the surgical incision and a repeated dose 3 hours later significantly reduced periand postoperative blood loss in cemented THA [65]. In Hungary, the use of a daily dose of 500$1000 \mathrm{mg}$ intravenous TXA is approved for prophylaxis to prevent local fibrinolysis.

According to a recently published meta-analysis, involving 1608 patients undergoing THR from 25 randomized controlled trials and reported on wound complications, the use of TXA leads to a slight reduction in the risk of developing wound complications compared to the control group [54]. We found the same, in our patients who received TXA, there was significantly reduced wound bleeding, a smaller frequency of wound dressing changes, and had a tendency to achieve a dry surgical wound earlier as compared with the control group. In the TXA group, the extent of thigh swelling was $50 \%$ less on the $7^{\text {th }}$ postoperative day, which can be attributed to the reduced formation of a deep haematoma. Our study examined the superficial haematoma on the skin surface as well, which was significantly smaller in size when compared with the control group. In a previous double-blinded, randomized study, deep haematoma volumes were measured with ultrasonography on the $7^{\text {th }}$ postoperative day in a group of patients receiving TXA and a control group not receiving TXA following THR [64]. The authors did not find a significant difference; however, the mean volume of haematoma was $28 \%$ smaller in their TXA group (270 mL (CI 209-331 mL) vs. $376 \mathrm{~mL}$ (CI 257-494 mL)). These findings can be explained by the pharmacological effect of TXA, as revealed in an early in vitro study, where the authors found that tranexamic acid inhibited clot lysis more efficiently when it was added before clot formation [112].

Previous studies have examined the factors which can cause prolonged wound healing and late periprosthetic infection. The postoperative haematoma formation and thigh swelling were found among the potential sources of infectious complications [93, 94]. A limitation of our study was a relatively small sample size, and therefore it was not powered to examine relatively rare complications such as periprosthetic joint infection. However, it provided evidence of a reduced presence of potential predisposing factors of infectious complications in patients receiving TXA.

Our second study has several strengths and considerable limitations. It was performed in a single university department with a large surgical volume, enrolled consecutive patients, and used a standardized surgical technique. The two compared groups were demographically 
similar and the number of patients was high enough to provide significant differences. Perioperative blood loss was monitored comprehensively via multiple end-points (i.e. intraoperative blood loss, drainage volume, Hb concentration, wound haematoma and drainage, duration of serous discharge). One of the limitations was the perioperative administration of a total of $1000 \mathrm{mg}$ TXA, which is lower dose than what used in some of the prior studies. Despite this arguably low dose, we found a significantly reduced postoperative blood loss, transfusion rate and decreased wound bleeding in the TXA treatment group, suggesting sufficient serum levels. In line with this, there are previous studies showing that $1000 \mathrm{mg}$ or even lower doses of TXA can effectively reduce blood loss and the postoperative transfusion requirement in THR $[15,63]$. Arguably, our study did not use randomisation; however, the two groups were clearly separated in time, and the only variable distinguishing the two groups was the use of TXA. In addition to the demonstrated decrease in the need of transfusions, the decreased incidence of minor bleeding complications may have the potential to provide an additional benefit in reducing the frequency of delayed infectious complications. Further investigations and analyses are necessary to provide direct evidence on this issue. 


\section{Conclusions}

The new findings of the above presented works can be summarized as the following:

1. Increased incidence of prolonged discharge from the drain site and elevated serous wound discharge were found using dabigatran etexilate if compared with enoxaparine.

2. The same amount of thigh volume increase was observed on the $7^{\text {th }}$ postoperative day after THR with either enoxaparine, dabigatran or rivaroxaban.

3. According to our knowledge, we reported the first clinical study examining the effect of perioperatively administered TXA in a well-defined subgroup of patients undergoing clearly cemented THR and anticoagulated postoperatively with rivaroxaban.

4. The extent of thigh swelling was about $50 \%$ less on the $7^{\text {th }}$ postoperative day, when TXA was used perioperatively during THR.

5. In addition to the well-known perioperative blood loss and transfusion rate reducing effect, our results demonstrate a significant reduction of postoperative minor bleeding complications using multiple end-points when administering TXA, including blood loss through drain site, surgical wound bleeding, the size of superficial haematoma and the tendency to achieve a dry surgical wound earlier. 


\section{Acknowledgements}

Firstly, I would like to express my gratitude to my supervisor and tutor, Krisztián Sisák M.D., habil., Ph.D. (Associate Professor, Director of the Orthopaedic Department, University of Szeged), for his excellent scientific guidance and continuous support of my research activities and my progression. I have had the opportunity to learn from him the basics of orthopaedic surgery, the value of thorough work and precision. I will always be grateful to him for his useful advice and instructions for my scientific publications and thesis.

I am grateful to Kálmán Tóth M.D., Ph.D., D.Sc. (Professor and former Head of the Orthopaedic Department, University of Szeged, Former Member of the Hungarian Academy of Sciences), who gave me the opportunity to start my postgraduate and scientific work at Orthopaedic Department. I am thankful to Professor Tóth for showing me the importance of research in a clinician's life and for his support in both the academic and personal areas of my life.

I am much obliged to Gyöngyi Horváth M.D., Ph.D., D.Sc. (Professor at the Department of Physiology, University of Szeged) for the possibility to become familiar with statistical methods and for her continuous support and advice on my publications.

Furthermore, I would like to say many thanks to all my colleagues at the Orthopaedic Department, especially to Gellért Sohár M.D., habil., Ph.D. and Hristifor Gálity M.D. for their continuous help and advice during my work. I greatly acknowledge all co-authors for helping my publications.

I am grateful to my parents and grandparents who raised and helped me during my studies, without them this work would not have been possible.

Last, but not least, I am thankful to my wife, Regina, for her patient love, support and help which made it possible for me to complete my scientific work, and to my little daughter, Olívia, whose adorable smile always cheered me up when I was lost between the lines.

I dedicate this work to the memory of the late Professor Kálmán Tóth. 


\section{References}

1. Lubbeke A, Silman AJ, Barea C, Prieto-Alhambra D, Carr AJ: Mapping existing hip and knee replacement registries in Europe. Health policy 2018, 122(5):548-557.

2. Oberweis BS, Nukala S, Rosenberg A, Guo Y, Stuchin S, Radford MJ, Berger JS: Thrombotic and bleeding complications after orthopedic surgery. American heart journal 2013, 165(3):427-433 e421.

3. Cohen AT, Tapson VF, Bergmann JF, Goldhaber SZ, Kakkar AK, Deslandes B, Huang W, Zayaruzny M, Emery L, Anderson FA, Jr. et al: Venous thromboembolism risk and prophylaxis in the acute hospital care setting (ENDORSE study): a multinational crosssectional study. Lancet 2008, 371(9610):387-394.

4. Gould MK, Garcia DA, Wren SM, Karanicolas PJ, Arcelus JI, Heit JA, Samama CM: Prevention of VTE in nonorthopedic surgical patients: Antithrombotic Therapy and Prevention of Thrombosis, 9th ed: American College of Chest Physicians EvidenceBased Clinical Practice Guidelines. Chest 2012, 141(2 Suppl):e227S-e277S.

5. Kahn SR, Lim W, Dunn AS, Cushman M, Dentali F, Akl EA, Cook DJ, Balekian AA, Klein RC, Le $\mathrm{H}$ et al: Prevention of VTE in nonsurgical patients: Antithrombotic Therapy and Prevention of Thrombosis, 9th ed: American College of Chest Physicians Evidence-Based Clinical Practice Guidelines. Chest 2012, 141(2 Suppl):e195S-e226S.

6. Cohen AT, Agnelli G, Anderson FA, Arcelus JI, Bergqvist D, Brecht JG, Greer IA, Heit JA, Hutchinson JL, Kakkar AK et al: Venous thromboembolism (VTE) in Europe. The number of VTE events and associated morbidity and mortality. Thrombosis and haemostasis 2007, 98(4):756-764.

7. Falck-Ytter Y, Francis CW, Johanson NA, Curley C, Dahl OE, Schulman S, Ortel TL, Pauker SG, Colwell CW, Jr.: Prevention of VTE in orthopedic surgery patients: Antithrombotic Therapy and Prevention of Thrombosis, 9th ed: American College of Chest Physicians Evidence-Based Clinical Practice Guidelines. Chest 2012, 141(2 Suppl):e278S-325S.

8. Flevas DA, Megaloikonomos PD, Dimopoulos L, Mitsiokapa E, Koulouvaris P, Mavrogenis AF: Thromboembolism prophylaxis in orthopaedics: an update. EFORT open reviews 2018, 3(4):136-148.

9. Farfan M, Bautista M, Bonilla G, Rojas J, Llinas A, Navas J: Worldwide adherence to ACCP guidelines for thromboprophylaxis after major orthopedic surgery: A systematic review of the literature and meta-analysis. Thrombosis research 2016, 141:163-170.

10. White RH: The epidemiology of venous thromboembolism. Circulation 2003, 107(23 Suppl 1):I4-8.

11. Scottish Intercollegiate Guidelines Network (SIGN) Prevention and management of venous thromboembolism. Available: http://www.sign.ac.uk/guidelines/fulltext/122/index.html. 2010.

12. Anderson FA, Jr., Spencer FA: Risk factors for venous thromboembolism. Circulation 2003, 107(23 Suppl 1):I9-16. 
13. Jensen CD, Steval A, Partington PF, Reed MR, Muller SD: Return to theatre following total hip and knee replacement, before and after the introduction of rivaroxaban: a retrospective cohort study. J Bone Joint Surg Br 2011, 93(1):91-95.

14. Borghi B, Borghi R: Blood-saving techniques. Transplantation proceedings 2011, 43(1):333-337.

15. Poeran J, Rasul R, Suzuki S, Danninger T, Mazumdar M, Opperer M, Boettner F, Memtsoudis SG: Tranexamic acid use and postoperative outcomes in patients undergoing total hip or knee arthroplasty in the United States: retrospective analysis of effectiveness and safety. Bmj 2014, 349:g4829.

16. Ye W, Liu Y, Liu WF, Li XL, Fei Y, Gao X: Comparison of efficacy and safety between oral and intravenous administration of tranexamic acid for primary total knee/hip replacement: a meta-analysis of randomized controlled trial. Journal of orthopaedic surgery and research 2020, 15(1):21.

17. OrthopedicsToday: Two VTE prophylaxis guidelines are now in agreement. (https://www.healio.com/news/orthopedics/20120611/two-vte-prophylaxis-guidelinesare-now-in-agreement):Published: 5th June 2012, Last accessed: 10th April 2021.

18. Leme LE, Sguizzatto GT: Prophylaxis of Venous Thromboembolism in Orthopaedic Surgery. Revista brasileira de ortopedia 2012, 47(6):685-693.

19. Geerts WH, Bergqvist D, Pineo GF, Heit JA, Samama CM, Lassen MR, Colwell CW: Prevention of venous thromboembolism: American College of Chest Physicians Evidence-Based Clinical Practice Guidelines (8th Edition). Chest 2008, 133(6 Suppl):381S-453S.

20. White RH, Romano PS, Zhou H, Rodrigo J, Bargar W: Incidence and time course of thromboembolic outcomes following total hip or knee arthroplasty. Archives of internal medicine 1998, 158(14):1525-1531.

21. Planes A, Vochelle N, Darmon JY, Fagola M, Bellaud M, Huet Y: Risk of deep-venous thrombosis after hospital discharge in patients having undergone total hip replacement: double-blind randomised comparison of enoxaparin versus placebo. Lancet 1996, 348(9022):224-228.

22. Kearon C, Akl EA, Ornelas J, Blaivas A, Jimenez D, Bounameaux H, Huisman M, King CS, Morris TA, Sood N et al: Antithrombotic Therapy for VTE Disease: CHEST Guideline and Expert Panel Report. Chest 2016, 149(2):315-352.

23. Jacobs JJ, Mont MA, Bozic KJ, Della Valle CJ, Goodman SB, Lewis CG, Yates AC, Jr., Boggio LN, Watters WC, 3rd, Turkelson CM et al: American Academy of Orthopaedic Surgeons clinical practice guideline on: preventing venous thromboembolic disease in patients undergoing elective hip and knee arthroplasty. The Journal of bone and joint surgery American volume 2012, 94(8):746-747.

24. National Institute for Health and Care Excellence (NICE). Venous thromboembolism in over 16s: reducing the risk of hospital-acquired deep vein thrombosis or pulmonary embolism. Published date: 21 March 2018, Last updated: 13 August 2019 Last accessed: 28th March 2021. 
25. Hungarian Ministry of Health, National Guideline: Reduction and Treatment of Thromboembolism. [Available in Hungarian. Magyar Egészségügyi Minisztérium Szakmai Irányelve: A thromboemboliák kockázatának csökkentése és kezelése]. ( https://old-kollegium.aeek.hu/site/index.html Updated: 26th Feb 2010 Last accessed: 10th April 2021).

26. Hoenig H, Rubenstein LV, Sloane R, Horner R, Kahn K: What is the role of timing in the surgical and rehabilitative care of community-dwelling older persons with acute hip fracture? Archives of internal medicine 1997, 157(5):513-520.

27. Guyatt GH, Akl EA, Crowther M, Gutterman DD, Schuunemann HJ: Executive summary: Antithrombotic Therapy and Prevention of Thrombosis, 9th ed: American College of Chest Physicians Evidence-Based Clinical Practice Guidelines. Chest 2012, 141(2 Suppl):7S-47S.

28. An VV, Phan K, Levy YD, Bruce WJ: Aspirin as Thromboprophylaxis in Hip and Knee Arthroplasty: A Systematic Review and Meta-Analysis. The Journal of arthroplasty 2016, 31(11):2608-2616.

29. Kahn SR, Shivakumar S: What's new in VTE risk and prevention in orthopedic surgery. Research and practice in thrombosis and haemostasis 2020, 4(3):366-376.

30. Tan CSS, Lee SWH: Warfarin and food, herbal or dietary supplement interactions: A systematic review. British journal of clinical pharmacology 2021, 87(2):352-374.

31. Ansell J, Hirsh J, Hylek E, Jacobson A, Crowther M, Palareti G: Pharmacology and management of the vitamin $\mathrm{K}$ antagonists: American College of Chest Physicians Evidence-Based Clinical Practice Guidelines (8th Edition). Chest 2008, $133(6$ Suppl):160S-198S.

32. Garcia DA, Baglin TP, Weitz JI, Samama MM: Parenteral anticoagulants: Antithrombotic Therapy and Prevention of Thrombosis, 9th ed: American College of Chest Physicians Evidence-Based Clinical Practice Guidelines. Chest 2012, 141(2 Suppl):e24S-e43S.

33. Bhandari M, Hirsh J, Weitz JI, Young E, Venner TJ, Shaughnessy SG: The effects of standard and low molecular weight heparin on bone nodule formation in vitro. Thrombosis and haemostasis 1998, 80(3):413-417.

34. Arepally GM: Heparin-induced thrombocytopenia. Blood 2017, 129(21):2864-2872.

35. Martel N, Lee J, Wells PS: Risk for heparin-induced thrombocytopenia with unfractionated and low-molecular-weight heparin thromboprophylaxis: a metaanalysis. Blood 2005, 106(8):2710-2715.

36. Warwick D: Prevention of venous thromboembolism in total knee and hip replacement. Circulation 2012, 125(17):2151-2155.

37. Muntz J: Thromboprophylaxis in orthopedic surgery: how long is long enough? Am J Orthop (Belle Mead NJ) 2009, 38(8):394-401.

38. Hull RD, Pineo GF, Francis C, Bergqvist D, Fellenius C, Soderberg K, Holmqvist A, Mant M, Dear R, Baylis B et al: Low-molecular-weight heparin prophylaxis using dalteparin in close proximity to surgery vs warfarin in hip arthroplasty patients: a 
double-blind, randomized comparison. The North American Fragmin Trial Investigators. Arch Intern Med 2000, 160(14):2199-2207.

39. Barnes GD, Ageno W, Ansell J, Kaatz S: Recommendation on the nomenclature for oral anticoagulants: communication from the SSC of the ISTH: reply. Journal of thrombosis and haemostasis : JTH 2015, 13(11):2132-2133.

40. Lassen MR, Gallus A, Raskob GE, Pineo G, Chen D, Ramirez LM, Investigators A-: Apixaban versus enoxaparin for thromboprophylaxis after hip replacement. The New England journal of medicine 2010, 363(26):2487-2498.

41. Lassen MR, Raskob GE, Gallus A, Pineo G, Chen D, Hornick P, investigators A-: Apixaban versus enoxaparin for thromboprophylaxis after knee replacement (ADVANCE-2): a randomised double-blind trial. Lancet 2010, 375(9717):807-815.

42. Madan S, Shah S, Dale P, Partovi S, Parikh SA: Use of novel oral anticoagulant agents in venous thromboembolism. Cardiovascular diagnosis and therapy 2016, 6(6):570581.

43. European Medicines Agency - Eliquis INN-apixaban, epar-poduct information. (https://www.ema.europa.eu/documents/overview/apixaban-accord-epar-medicineoverview_hu.pdf Released 28th May 2011; Last accessed: 29th March 2021).

44. Kawai Y, Fuji T, Fujita S, Kimura T, Ibusuki K, Abe K, Tachibana S: Edoxaban versus enoxaparin for the prevention of venous thromboembolism after total knee or hip arthroplasty: pooled analysis of coagulation biomarkers and primary efficacy and safety endpoints from two phase 3 trials. Thrombosis journal 2016, 14:48.

45. Bereczky Z, Olah Z, Ajzner E, Kappelmayer J: [Laboratory aspects of novel oral anticoagulant treatment]. Orvosi hetilap 2017, 158(49):1930-1945.

46. Kubitza D, Berkowitz SD, Misselwitz F: Evidence-Based Development and Rationale for Once-Daily Rivaroxaban Dosing Regimens Across Multiple Indications. Clinical and applied thrombosis/hemostasis : official journal of the International Academy of Clinical and Applied Thrombosis/Hemostasis 2016, 22(5):412-422.

47. Eriksson BI, Borris LC, Friedman RJ, Haas S, Huisman MV, Kakkar AK, Bandel TJ, Beckmann H, Muehlhofer E, Misselwitz F et al: Rivaroxaban versus enoxaparin for thromboprophylaxis after hip arthroplasty. The New England journal of medicine 2008, 358(26):2765-2775.

48. Kakkar AK, Brenner B, Dahl OE, Eriksson BI, Mouret P, Muntz J, Soglian AG, Pap $\mathrm{AF}$, Misselwitz F, Haas $\mathrm{S}$ et al: Extended duration rivaroxaban versus short-term enoxaparin for the prevention of venous thromboembolism after total hip arthroplasty: a double-blind, randomised controlled trial. Lancet 2008, 372(9632):31-39.

49. Eriksson BI, Dahl OE, Buller HR, Hettiarachchi R, Rosencher N, Bravo ML, Ahnfelt L, Piovella F, Stangier J, Kalebo P et al: A new oral direct thrombin inhibitor, dabigatran etexilate, compared with enoxaparin for prevention of thromboembolic events following total hip or knee replacement: the BISTRO II randomized trial. J Thromb Haemost 2005, 3(1):103-111.

50. Eriksson BI, Dahl OE, Rosencher N, Kurth AA, van Dijk CN, Frostick SP, Prins MH, Hettiarachchi R, Hantel S, Schnee J et al: Dabigatran etexilate versus enoxaparin for 
prevention of venous thromboembolism after total hip replacement: a randomised, double-blind, non-inferiority trial. Lancet 2007, 370(9591):949-956.

51. Eriksson BI, Dahl OE, Huo MH, Kurth AA, Hantel S, Hermansson K, Schnee JM, Friedman RJ: Oral dabigatran versus enoxaparin for thromboprophylaxis after primary total hip arthroplasty (RE-NOVATE II*). A randomised, double-blind, non-inferiority trial. Thromb Haemost 2011, 105(4):721-729.

52. Eriksson BI, Dahl OE, Ahnfelt L, Kalebo P, Stangier J, Nehmiz G, Hermansson K, Kohlbrenner V: Dose escalating safety study of a new oral direct thrombin inhibitor, dabigatran etexilate, in patients undergoing total hip replacement: BISTRO I. J Thromb Haemost 2004, 2(9):1573-1580.

53. Uchino K, Hernandez AV: Dabigatran association with higher risk of acute coronary events: meta-analysis of noninferiority randomized controlled trials. Archives of internal medicine 2012, 172(5):397-402.

54. Sukeik M, Alshryda S, Powell J, Haddad FS: The effect of tranexamic acid on wound complications in primary total Hip Arthroplasty: A meta-analysis. The surgeon : journal of the Royal Colleges of Surgeons of Edinburgh and Ireland 2020, 18(1):53-61.

55. Shah A, Palmer AJR, Klein AA: Strategies to minimize intraoperative blood loss during major surgery. The British journal of surgery 2020, 107(2):e26-e38.

56. Alshryda S, Sukeik M, Sarda P, Blenkinsopp J, Haddad FS, Mason JM: A systematic review and meta-analysis of the topical administration of tranexamic acid in total hip and knee replacement. The bone \& joint journal 2014, 96-B(8):1005-1015.

57. Fergusson DA, Hebert PC, Mazer CD, Fremes S, MacAdams C, Murkin JM, Teoh K, Duke PC, Arellano R, Blajchman MA et al: A comparison of aprotinin and lysine analogues in high-risk cardiac surgery. The New England journal of medicine 2008, 358(22):2319-2331.

58. Padhi S, Kemmis-Betty S, Rajesh S, Hill J, Murphy MF, Guideline Development G: Blood transfusion: summary of NICE guidance. Bmj 2015, 351:h5832.

59. European Medical Agency: Modificaton of European marketing authorization of tranexamic acid based on scientific conclusions. (https://ec.europa.eu/health/documents/communityregister/2012/20121010124211/anx_124211_hu.pdf):(Hungarian) Last accessed 12th April 2021.

60. Cai J, Ribkoff J, Olson S, Raghunathan V, Al-Samkari H, DeLoughery TG, Shatzel JJ: The many roles of tranexamic acid: An overview of the clinical indications for TXA in medical and surgical patients. European journal of haematology 2020, 104(2):79-87.

61. Franchini M, Mengoli C, Marietta M, Marano G, Vaglio S, Pupella S, Mannucci PM, Liumbruno GM: Safety of intravenous tranexamic acid in patients undergoing majororthopaedic surgery: a meta-analysis of randomised controlled trials. Blood transfusion = Trasfusione del sangue 2018, 16(1):36-43.

62. Sukeik M, Alshryda S, Haddad FS, Mason JM: Systematic review and meta-analysis of the use of tranexamic acid in total hip replacement. J Bone Joint Surg Br 2011, 93(1):3946. 
63. Fillingham YA, Ramkumar DB, Jevsevar DS, Yates AJ, Shores P, Mullen K, Bini SA, Clarke HD, Schemitsch E, Johnson RL et al: The Efficacy of Tranexamic Acid in Total Hip Arthroplasty: A Network Meta-analysis. The Journal of arthroplasty 2018, 33(10):3083-3089 e3084.

64. Benoni G, Fredin H, Knebel R, Nilsson P: Blood conservation with tranexamic acid in total hip arthroplasty: a randomized, double-blind study in 40 primary operations. Acta orthopaedica Scandinavica 2001, 72(5):442-448.

65. Ekback G, Axelsson K, Ryttberg L, Edlund B, Kjellberg J, Weckstrom J, Carlsson O, Schott U: Tranexamic acid reduces blood loss in total hip replacement surgery. Anesth Analg 2000, 91(5):1124-1130.

66. Johansson T, Pettersson LG, Lisander B: Tranexamic acid in total hip arthroplasty saves blood and money: a randomized, double-blind study in 100 patients. Acta Orthop 2005, 76(3):314-319.

67. Irwin A, Khan SK, Jameson SS, Tate RC, Copeland C, Reed MR: Oral versus intravenous tranexamic acid in enhanced-recovery primary total hip and knee replacement: results of 3000 procedures. Bone Joint J 2013, 95-B(11):1556-1561.

68. Goobie SM: Tranexamic acid: still far to go. British journal of anaesthesia 2017, 118(3):293-295.

69. Chauncey JM, Wieters JS: Tranexamic Acid. In: StatPearls. edn. Treasure Island (FL); 2021.

70. Nieto JA, Espada NG, Merino RG, Gonzalez TC: Dabigatran, Rivaroxaban and Apixaban versus Enoxaparin for thomboprophylaxis after total knee or hip arthroplasty: Pool-analysis of phase III randomized clinical trials. Thromb Res 2012, 130(2):183-191.

71. Gomez-Outes A, Terleira-Fernandez AI, Suarez-Gea ML, Vargas-Castrillon E: Dabigatran, rivaroxaban, or apixaban versus enoxaparin for thromboprophylaxis after total hip or knee replacement: systematic review, meta-analysis, and indirect treatment comparisons. Bmj, 344:e3675.

72. Gill SK, Theodorides A, Smith N, Maguire E, Whitehouse SL, Rigby MC, Ivory JP: Wound problems following hip arthroplasty before and after the introduction of a direct thrombin inhibitor for thromboprophylaxis. Hip international : the journal of clinical and experimental research on hip pathology and therapy 2011, 21(6):678-683.

73. Jameson SS, Rymaszewska M, Hui AC, James P, Serrano-Pedraza I, Muller SD: Wound complications following rivaroxaban administration: a multicenter comparison with low-molecular-weight heparins for thromboprophylaxis in lower limb arthroplasty. $J$ Bone Joint Surg Am 2012, 94(17):1554-1558.

74. Niskanen RO, Korkala OL: Tranexamic acid reduces blood loss in cemented hip arthroplasty: a randomized, double-blind study of 39 patients with osteoarthritis. Acta orthopaedica 2005, 76(6):829-832.

75. Clave A, Fazilleau F, Dumser D, Lacroix J: Efficacy of tranexamic acid on blood loss after primary cementless total hip replacement with rivaroxaban thromboprophylaxis: A case-control study in 70 patients. Orthop Traumatol Surg Res 2012, 98(5):484-490. 
76. The European Agency for the Evaluation of Medicinal Products, Committee for Medicinal Products for Human Use (CHMP), Guideline on clinical investigation of medicinal products for prophylaxis of high intra- and post-operative venous thromboembolic risk. (last accessed: 28th March 2021) Available at: http://www.ema.europa.eu/docs/en_GB/document_library/Scientific_guideline/2009/0 9/WC500003301.pdf(ed)^(eds)

77. Fujisawa M, Naito M, Asayama I, Kambe T, Koga K: Effect of calf-thigh intermittent pneumatic compression device after total hip arthroplasty: comparative analysis with plantar compression on the effectiveness of reducing thrombogenesis and leg swelling. J Orthop Sci 2003, 8(6):807-811.

78. Jones PR, Pearson J: Anthropometric determination of leg fat and muscle plus bone volumes in young male and female adults. J Physiol 1969, 204(2):63P-66P.

79. Nadler SB, Hidalgo JH, Bloch T: Prediction of blood volume in normal human adults. Surgery 1962, 51(2):224-232.

80. Bourke DL, Smith TC: Estimating allowable hemodilution. Anesthesiology 1974, 41(6):609-612.

81. National Institute for Health and Clinical Excellence (NICE): Venous thromboembolism - reducing the risk: NICE guideline Available: http://guidance.nice.org.uk/CG92/NICEGuidance/pdf/English. 2010.

82. European Medicines Agency: Pradaxa. Summary of Product Characteristics. Available: http://www.emea.europa.eu/docs/en_GB/document_library/EPAR__Summary_for_the public/human/000829/WC500041060.pdf. 2011.

83. Hirsh J, Bauer KA, Donati MB, Gould M, Samama MM, Weitz JI: Parenteral anticoagulants: American College of Chest Physicians Evidence-Based Clinical Practice Guidelines (8th Edition). Chest 2008, 133(6 Suppl):141S-159S.

84. Hankey GJ, Eikelboom JW: Dabigatran Etexilate : A New Oral Thrombin Inhibitor. Circulation 2011, 123:1436-1450.

85. Ramos-Esquivel A: Monitoring anticoagulant therapy with new oral agents. World journal of methodology 2015, 5(4):212-215.

86. Pollack CV, Jr., Reilly PA, Eikelboom J, Glund S, Verhamme P, Bernstein RA, Dubiel R, Huisman MV, Hylek EM, Kamphuisen PW et al: Idarucizumab for Dabigatran Reversal. The New England journal of medicine 2015, 373(6):511-520.

87. Bloch BV, Patel V, Best AJ: Thromboprophylaxis with dabigatran leads to an increased incidence of wound leakage and an increased length of stay after total joint replacement. The bone \& joint journal 2014, 96-B(1):122-126.

88. Mayer A, Schuster P, Fink B: A comparison of apixaban and dabigatran etexilate for thromboprophylaxis following hip and knee replacement surgery. Archives of orthopaedic and trauma surgery 2017, 137(6):797-803.

89. Highcock AJ, As-Sultany M, Finley R, Donnachie NJ: A Prospective Cohort Comparative Study of Rivaroxaban, Dabigatran, and Apixaban Oral 
Thromboprophylaxis in 2431 Hip and Knee Arthroplasty Patients: Primary Efficacy Outcomes and Safety Profile. The Journal of arthroplasty 2020, 35(11):3093-3098.

90. Cevirme D, Savluk OF, Basaran EK, Aksoy R, Elibol A, Bas T, Keser S, Adademir T, Yilmaz B: Effects of anticoagulant drugs on wound healing process in a rat model: a comparative study. Journal of wound care 2020, 29(1):44-50.

91. Andrews HJ, Arden GP, Hart GM, Owen JW: Deep infection after total hip replacement. J Bone Joint Surg Br 1981, 63-B(1):53-57.

92. Franco JA, Baer H, Enneking WF: Airborne contamination in orthopedic surgery. Evaluation of laminar air flow system and aspiration suit. Clin Orthop Relat Res 1977(122):231-243.

93. Freeman MA, Challis JH, Zelezonski J, Jarvis ID: Sepsis rates in hip replacement surgery with special reference to the use of ultra clean air. Archiv fur orthopadische und Unfall-Chirurgie 1977, 90(1):1-14.

94. Wilson PD, Jr.: Joint replacement. South Med J 1977, 70 Suppl 1:55-60.

95. Warwick D, Bannister GC, Glew D, Mitchelmore A, Thornton M, Peters TJ, Brookes S: Perioperative low-molecular-weight heparin. Is it effective and safe. J Bone Joint Surg $\operatorname{Br} 1995$, 77(5):715-719.

96. Gaine WJ, Ramamohan NA, Hussein NA, Hullin MG, McCreath SW: Wound infection in hip and knee arthroplasty. J Bone Joint Surg Br 2000, 82(4):561-565.

97. McNally MA, Cooke EA, Harding ML, Mollan RA: Attitudes to, and utilization of, low molecular weight heparins in joint replacement surgery. J R Coll Surg Edinb 1997, 42(6):407-409.

98. Dolinger O, Souza GM, Melo GB, Filho PPG: Surgical site infections in primary total hip and knee replacement surgeries, hemiarthroplasties, and osteosyntheses at a Brazilian university hospital. Am J Infect Control 2010, 38(3):246-248.

99. Bonnevialle P, Bonnomet F, Philippe R, Loubignac F, Rubens-Duval B, Talbi A, Le Gall C, Adam P: Early surgical site infection in adult appendicular skeleton trauma surgery: A multicenter prospective series. Orthop Traumatol Surg Res 2012, 98(6):684689.

100. Parker MJ, Roberts CP, Hay D: Closed suction drainage for hip and knee arthroplasty. A meta-analysis. J Bone Joint Surg Am 2004, 86-A(6):1146-1152.

101. Matziolis D, Matziolis G, Perka C: Thromboembolism prophylaxis with dabigatran leads to lower perioperative blood loss than with dalteparin in primary knee arthroplasty. Arch Orthop Trauma Surg 2011, 131(12):1739-1743.

102. Walmsley PJ, Kelly MB, Hill RM, Brenkel I: A prospective, randomised, controlled trial of the use of drains in total hip arthroplasty. J Bone Joint Surg Br 2005, 87(10):1397-1401.

103. Mengal B, Aebi J, Rodriguez A, Lemaire R: [A prospective randomized study of wound drainage versus non-drainage in primary total hip or knee arthroplasty]. Rev Chir Orthop Reparatrice Appar Mot 2001, 87(1):29-39. 
104. Nanni M, Perna F, Calamelli C, Donati D, Ferrara O, Parlato A, D'Arienzo M, Faldini C: Wound drainages in total hip arthroplasty: to use or not to use? Review of the literature on current practice. Musculoskelet Surg 2013, 97(2):101-107.

105. Benoni G, Lethagen S, Nilsson P, Fredin H: Tranexamic acid, given at the end of the operation, does not reduce postoperative blood loss in hip arthroplasty. Acta orthopaedica Scandinavica 2000, 71(3):250-254.

106. Ido K, Neo M, Asada Y, Kondo K, Morita T, Sakamoto T, Hayashi R, Kuriyama S: Reduction of blood loss using tranexamic acid in total knee and hip arthroplasties. Archives of orthopaedic and trauma surgery 2000, 120(9):518-520.

107. Yamasaki S, Masuhara K, Fuji T: Tranexamic acid reduces blood loss after cementless total hip arthroplasty-prospective randomized study in 40 cases. Int Orthop 2004, 28(2):69-73.

108. Clave A, Gerard R, Lacroix J, Baynat C, Danguy des Deserts M, Gatineau F, Mottier D: A randomized, double-blind, placebo-controlled trial on the efficacy of tranexamic acid combined with rivaroxaban thromboprophylaxis in reducing blood loss after primary cementless total hip arthroplasty. The bone \& joint journal 2019, 101-B(2):207212.

109. Rajesparan K, Biant LC, Ahmad M, Field RE: The effect of an intravenous bolus of tranexamic acid on blood loss in total hip replacement. The Journal of bone and joint surgery British volume 2009, 91(6):776-783.

110. Claeys MA, Vermeersch N, Haentjens P: Reduction of blood loss with tranexamic acid in primary total hip replacement surgery. Acta chirurgica Belgica 2007, 107(4):397401.

111. Hsu CH, Lin PC, Kuo FC, Wang JW: A regime of two intravenous injections of tranexamic acid reduces blood loss in minimally invasive total hip arthroplasty: a prospective randomised double-blind study. The bone \& joint journal 2015, 97 B(7):905-910.

112. Krishnamurti C, Vukelja SJ, Alving BM: Inhibitory effects of lysine analogues on t-PA induced whole blood clot lysis. Thrombosis research 1994, 73(6):419-430. 
10. Annex 